\title{
Políticas del gobierno mexicano en la región fronteriza norte*
}

\author{
J. Mario Herrera Ramos
}

En el presente artículo se analizan los programas y politicas instrumentadas por el gobierno mexicano desde 1848 en la región fronteriza norte. El objetivo central de todos ellos ha sido integrar económica, política y socialmente esa región al resto del país. Se evalúan aquí los resultados obtenidos en relación con el objetivo mencionado, y se concluye que tal objetivo nunca se ha logrado; el autor cree por tanto necesario cuestionar seriamente la validez de la integración como elemento fundamental en la política regional y urbana en la frontera norte de México.

\section{Introducción}

Dos principios generales han permeado a las políticas del gobierno mexicano en la región fronteriza norte (RFN): el nacionalismo, con todas sus implicaciones, y la conceptualización de la frontera como una región periférica, tanto en términos sociopolíticos como económicos.

El nacionalismo mexicano, como cualquier otro, ha tenido efectos positivos y negativos pero, en términos generales, se ha utilizado como instrumento para lograr la unidad nacional. De ahí que la integración de una región considerada como periférica tal como la RFN, se haya constituido en un objetivo estratégico dentro de las distintas políticas y programas del gobierno hacia esta región.

Durante muchos años, la RFN tenía una escasa población con características similares en todo el norte de México. Era entonces considerada como una región "débil" carente del grado de cohesión que se pensaba existía en la zona central y sur del país. Era una región "que debía ser integrada al resto de la economia". La tarea era pues "reforzarla", hacerla más fuerte y tan independiente como el resto del país.

La idea de que la RFN debe ser integrada al resto del país nunca ha sido cuestionada. "Al final de los años treinta, la frontera de los Estados Unidos había sido integrada a la economía de los Estados Unidos, mientras que algunos pueblos de la frontera mexicana estaban escasamente vinculados al resto del país. Como resultado, las formas de vida, los patrones

* El presente documento es una versión modificada del capitulo $\mathrm{V}$ de mi tesis doctoral. Ambos trabajos no hubieran sido posibles sin la ayuda incondicional de Nair Anaya. Agradezco los comentarios del Dr. Gustavo Garza. Agradezco también la ayuda económica de Conacyt $y$ de The London School of Economics. Las opiniones aquí presentadas son responsabilidad exclusiva del autor. 


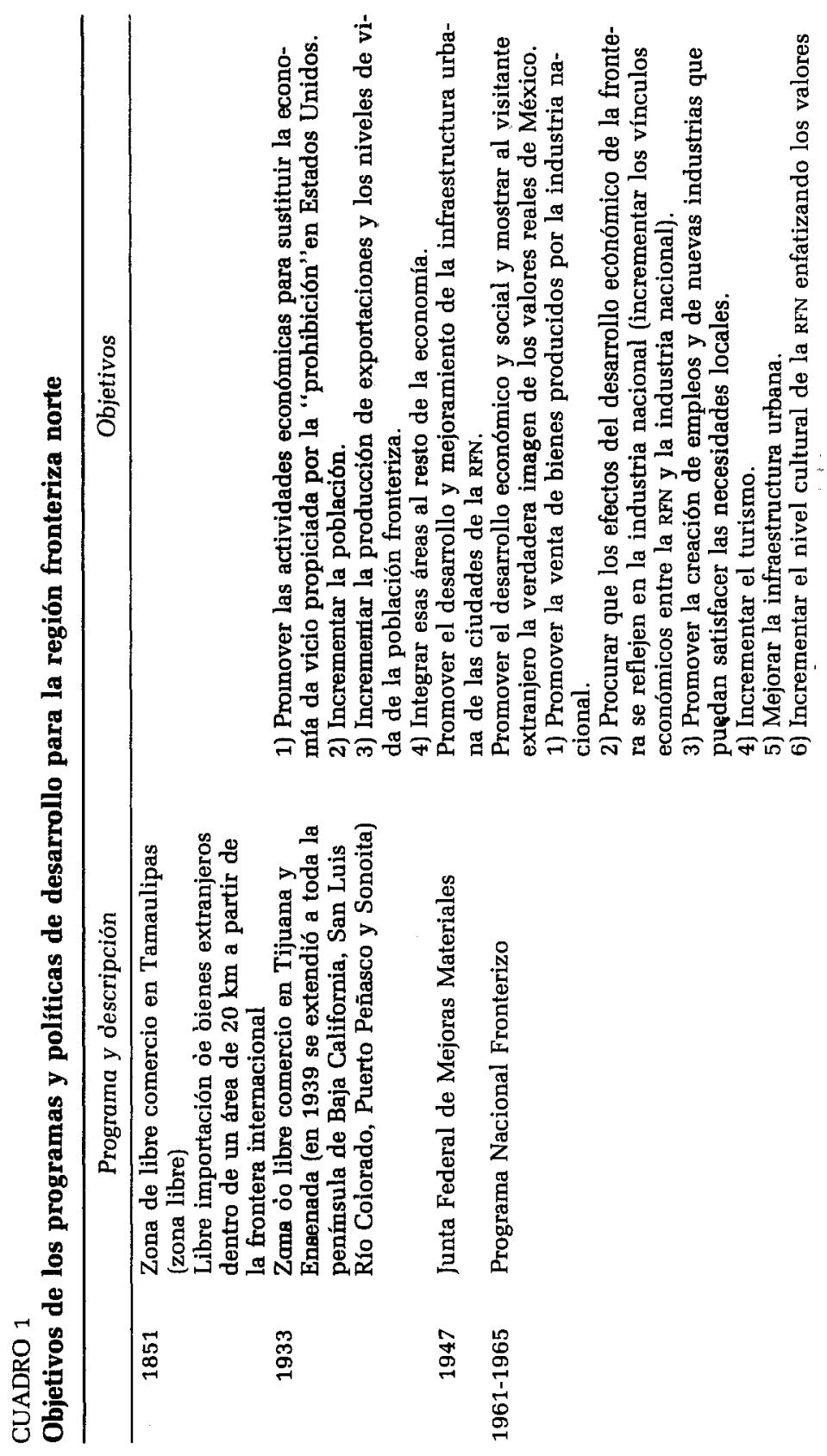




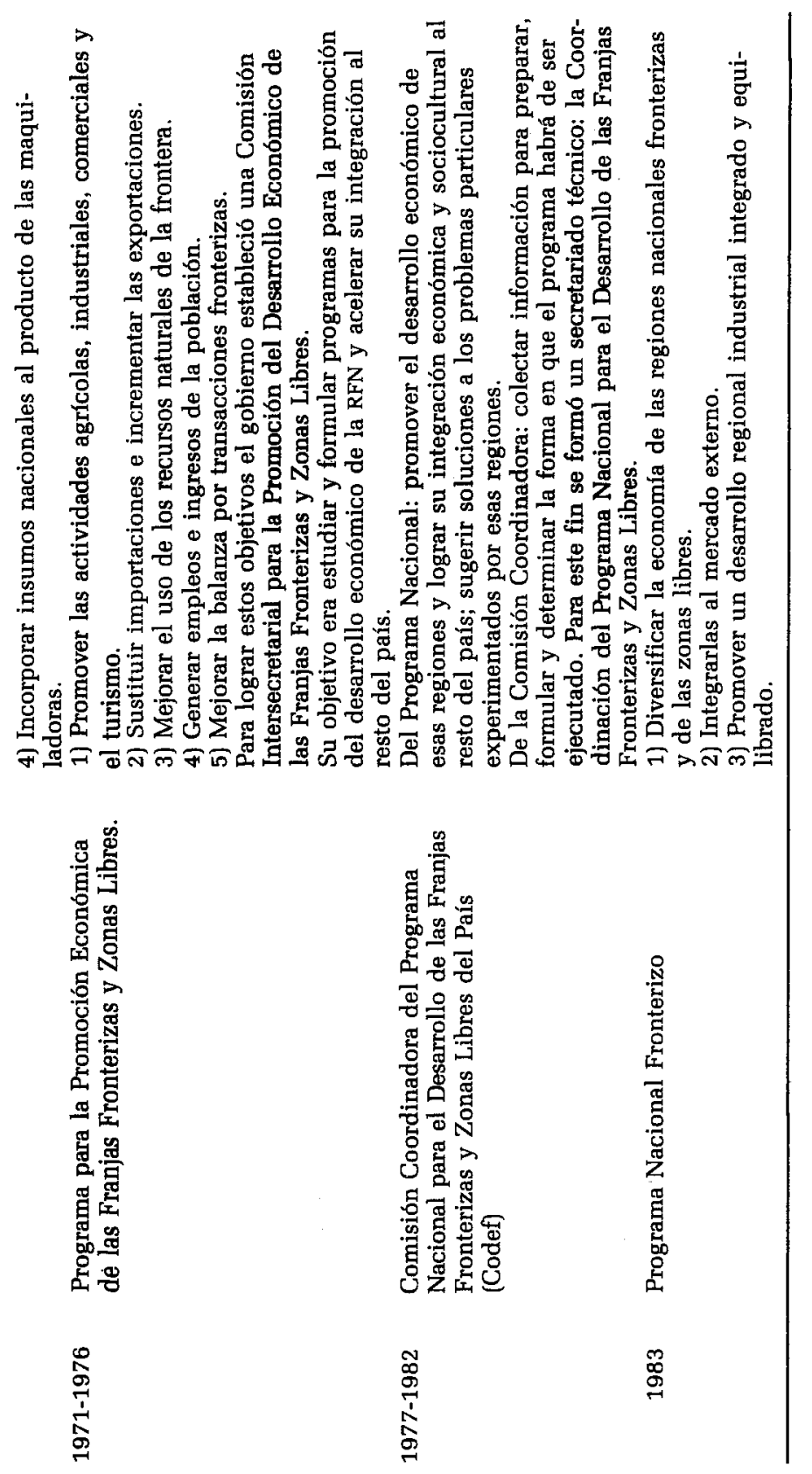


de trabajo, comercio y consumo del país vecino fueron adoptadas."1 Por tanto, se deberían instrumentar políticas cuyo objetivo fuera promover esa integración.

Dicho objetivo ha sido la característica sobresaliente de los más importantes programas y políticas del gobierno mexicano hacia la RFN (véase el cuadro 1).

El propósito de este artículo es evaluar los resultados de esos programas en función de la cuestión de la "integración"; la conclusión general que se obtiene es que han sido un fracaso, pues desde 1848 la RFN nunca ha sido "integrada".

\section{Programas y políticas}

1. Zonas de libre comercio

Después de la guerra de 1846-1848, algunas ciudades que originalmente no estaban localizadas en la frontera sintieron un cambio de situación. Algunas de ellas habían sido centros comerciales con importantes vínculos con otros centros del norte de México. Después de la guerra, esos vínculos comerciales (así como todas aquellas cuestiones asociadas con una pérdida de territorio), se vieron fuertemente afectados. Sus relaciones comerciales ahora eran catalogadas como importaciones y exportaciones, y por tanto susceptibles de pagar impuestos. Lo que en un momento pudo ser considerado como comercio interregional, se tornó comercio internacional.

Paso del Norte (hoy Ciudad Juárez) ejemplifica esas transformaciones. ${ }^{2}$ Pueblos de la frontera que anteriormente habian experimentado una situación similar se convirtieron en ejemplos de esas posibles consecuencias. Tal es el caso de algunos pueblos localizados en la frontera Tamaulipas-Texas (1836): ${ }^{3}$

Las nuevas comunidades en la frontera de Texas se convirtieron en parte de an sistema agrícola, comercial e industrial que estaba avanzando rápidamente. Ellas disfrutaban el libre flujo del comercio interno, tarifas comparativa-

${ }^{1}$ Eliseo Mendoza Berrueto, Historia de los programas federales para el desarrollo económico de la frontera norte, mimeógrafo, Ciudad Juárez, 1979, pp. 9-10 (publicado en Mario Ojeda (comp.) Administración del desarrollo de la Jrontera norte, México, El Colegio de México, 1982, pp. 39-84.

2 Véase, Óscar Martínez, Border Boom Town: Ciudad Juárez since 1848, University of Texas Press, Austin, 1975 y 1978, caps. 1 y 2.

${ }^{3}$ Desde 1750 había asentamientos españoles en la rivera norte del Bravo. Tal era el caso de Reynosa, Camargo, Laredo y Mier. Después de la guerra de 1846-1848, asentamientos mexicanos como Laredo se establecieron en la rivera sur. Los otros asentamientos mexicanos y españoles mantuvieron su nombre, pero los localizados en el lado estadunidense los cambiaron. 
mente bajas, y el privilegio de transportar bienes extranjeros por el territorio norteamericano sin pagar impuestos si esas mercancias iban a exportarse a México. Los puebi.'s de la frontera de Tamaulipas, por otra parte, no sólo carecían de una base industrial y comercial, sino también, debido a factores geográficos y de transporte, se encontraron efectivamente aislados de los centros de producción de México. (...) Los residentes fronterizos pagaban impuestos prohibitivos a la im;irtación de bienes trádos del otro lado del río. Antes de que se fijara la frontera, esos impuestos no existían.4

Las florecientes actividades económicas de Texas, y las condiciones de depresión del lado mexicano propiciaron una corriente migratoria hacia el norte. Ello fue considerado como una peligrosa tendencia a la despoblación. Para modificar este fenómeno, el gobierno central facilitó desde 1849 las condiciones al comercio en la frontera de Tamaulipas. En 1858 se le otorgó el estatus de zona de libre comercio, aprobado por el gobierno federal en 1861.5 El régimen de la zona libre se extendió a toda la RFN en 1885. Este estatus, otorgado en parte como un favor político por el apoyo ofrecido por los estados fronterizos a la presidencia de Porfirio Diaz, y en parte por razones económicas, no dejó de ser impugnado por los Estados Unidos. En 1991 se agregó una cláusula que limitaba efectivamente cualquier clase de vínculo comercial de la RFN con el resto de México: "La nueva cláusula estipulaba que cualquier producto manufacturado en la zona, sea éste integrado por materias primas domésticas o extranjeras, estaba sujeto a un impuesto regular de $90 \%$ si era transportado al interior."6 Los efectos de tal regulación permanecieron aún cuando se hicieron enmiendas más favorables.

Parece que las ciudades fronterizas se vieron beneficiadas mientras duró el régimen de zona libre. Pero esos beneficios no sólo tenían efectos en sus contrapartes estadunidenses, sino también sobre algunos comerciantes del interior de México. Esto era cierto al menos para ciudades que para fines del siglo pasado estaban floreciendo como Paso del Norte (Ciudad Juárez):

El que México estableciera una zona de libre comercio en Ciudad Juárez en 1895 afectó inicialmente a los comerciantes al menudeo de El Paso (Estados Unidos). Sin embargo su desaparición en 1905, debido a presiones tanto de los comerciantes norteamericanos como de los comerciantes del interior de

4 Martínez, op. cit., p. 13.

5 Debe notarse que esta nueva situación, además de los efectos de la guerra civil, amenazó la prosperidad de los establecimientos comerciales en el lado estadunidense. La respuesta del congreso de los Estados Unidos no se hizo esperar. El gobierno mexicano fue presionado para que suprimiera el estatus de libre comercio. Una breve reseña de los problemas asociados con la zona de libre comercio se encuentra en Martinez, op. cit., pp. 15-17.

${ }^{B}$ Idem, p. 28. 
México, y la recesión económica general, dio inicio a un periodo de prosperidad en las tiendas de El Paso".?

Así, para 1905 la zona de libre comercio había sido eliminada. Oficialmente se dijo que ello obedeció a que las vías ferroviarias en la ciudad de México facilitaban el transporte del interior a la RFN. También se dijo que no había logrado los objetivos para los cuales fue creada, o sea un incremento en la población. Tal parece que a principios de siglo hubo una disminución en la población fronteriza. Pero la disminución estaba relacionada con factores diferentes del régimen de zona libre. En Ciudad Juárez, por ejemplo, estaba vinculada a la falta de agua, a la inflación y a la devaluación. La carencia de agua afectaba directamente a la agricultura, en ese entonces la principal actividad económica.

De igual manera el comercio se estancó, resultando en una mayor disminución de negocios, los precios de la tierra disminuyeron drásticamente y el costo de vida se fue por los cielos. La pérdida de población continuaba. Durante el mejor periodo del régimen de zona libre el municipio de Juárez tenía una población de entre 20000 y 29000 personas. Para 1900 esa población había disminuido a $8 \mathbf{7 8 0 . 8}$

Así, aún durante las primeras décadas de la existencia de la frontera, era claro que "su problema" no radicaba en la falta de "integración". También era claro que en la raíz del problema estaban algunas cuestiones fuera del control de la población fronteriza. En 1933 el gobierno federal restableció parcialmente el régimen de libre comercio. Este estatus fue sólo otorgado a Tijuana y Ensenada. Después fue extendido a toda la península, a San Luis Río Colorado y a Sonoita en Sonora (a Nogales y Agua Prieta también se les dio el estatus de perímetros libres). El estatus debía terminar en 1956 pero fue ampliado hasta 1966. Sin embargo, como se verá más adelante, el Programa Nacional Fronterizo lo reintrodujo porque, al igual que en los años treinta, esas áreas prácticamente no tenían vínculos económicos con la parte central de México.

Su reintroducción en 1933 a algunas partes selectas de la frontera noroeste no implicaba los mismos problemas que había acarreado hasta 1905. Se reintrodujo para aminorar los efectos de la recesión económica norteamericana, y algunos problemas sociales. Ello de ninguna manera implica que el resto de la RFN no haya sufrido los efectos de la depresión de 19291933, o que no tuviesen agudos problemas. Las razones de tal discrimina-

\footnotetext{
7 Mario T. García, Desert Immigrants: The Mexicans of El Paso, 1880-1920, Yale University Press, New Haven y Londres, 1981, p. 25. Véase también Martínez, op. cit., capítulo dos. 8 Martínez, op. cit., p. 30. Véase también Ulises Irigoyen, "Vigoricemos las ciudades fronterizas con el comercio libre", Revista de Economía, vol. 4, núm. 9, feb. de 1941.
} 
ción fueron los efectos colaterales que hubiese acarreado la extensión del régimen de libre comercio al resto de la RFN. Éstas eran las zonas mejor comunicadas y más pobladas de la RFN. Era política y económicamente inocuo introducir el régimen de zona libre a las áreas de la RFN menos comunicadas con el interior de México: las del noroeste. Lo anterior implica una crítica severa al argumento (y supuesto del gobierno) de que el régimen de zona libre se dirigió a resolver los problemas de la RFN, o sea la falta de población. ${ }^{9}$ En realidad ello apunta hacia un problema de directa contradicción entre lo que podemos llamar el interés regional y el interés nacional.

\section{La Junta Federal de Mejoras Materiales}

Este programa no se dirigió exclusivamente hacia la RFN. Era un programa nacional dirigido a los entonces mayores centros urbanos del país, algunos localizados en la RFN. Fue financiado mediante un cargo extra a los impuestos de exportación e importación ( 3 y $2 \%$, respectivamente). No tuvo un efecto significante en la RFN. Además, no respondía directamente a los problemas enfrentados por esa región.

3. El Programa Nacional Fronterizo (Pronaf)

Probablemente este fue uno de los primeros intentos federales para poner en marcha un programa de desarrollo regional. ${ }^{10}$ Tras algunos años de planeación sectorial, este programa fue, al menos en el papel, un intento por promover el desarrollo de una región en particular mediante un paquete de incentivos económicos y subsidios. El Pronaf era una agencia descentralizada financiada por el gobierno federal con objetivos bastante amplios y alejados de la realidad.

Los dos principales instrumentos usados por Pronaf para obtener sus objetivos fueron el financiamiento de obras públicas en los principales centros urbanos y el restablecimiento de la zona de libre comercio (terminada en 1905), aunque con ciertas modificaciones.

Los principales instrumentos del régimen de zona libre se encontrajan bajo la administración directa de la Secretaría de Hacienda y la Secrearía de Industria y Comercio. El Pronaf era una especie de intermediario in poder alguno para decidir el uso y manejo del régimen de zona libre.

$\mathrm{Al}$ régimen de zona libre se le dio un nuevo nombre ("régimen de ranja libre") en virtud de que su aplicación se redujo a una franja de 20 un de ancho delimitada por una línea paralela imaginaria a la frontera on Estados Unidos. No era, estrictamente, una zona de libre comercio.

\footnotetext{
${ }^{9}$ Sobre este punto véase, en particular, Irigoyen, op. cit.

${ }^{10}$ El primero de esos intentos fue el desarrollo de proyectos de cuencas hidrológicas de nes de 1940.
} 
Se impusieron restricciones diseñadas especialmente para cu mplir los objetivos del programa. La Secretaría de Hacienda mantuvo bajo su control la imposición de tarifas e impuestos a la importación. Artículos no producidos en la RFN y que se tuvieran que importar de Estados Unidos estaban sujetos a impuestos de importación, siempre y cuando esos artículos fuesen producidos por firmas mexicanas no fronterizas y que estas quisieran venderlos en la RFN. Se protegía, pues, el mercado fronterizo, para las industrias mexicanas no fronterizas. Las firmas no fronterizas tenían que registrarse en Pronaf. Además de esta protección tenían derecho a un subsidio sobre impuestos mercantiles resultantes de sus ventas en la RFN (1.8\%). También disfrutaban de un descuento de $20-25 \%$ sobre sus cos-

CUADRO 2

Inversión del Pronaf (millones de pesos)

\begin{tabular}{lcrr}
\hline & 1962 & 1963 & Hasta 1967 \\
\hline Tijuana & 10.0 & 6.0 & 37.0 \\
Mexicali & - & 20.3 & $46.1^{*}$ \\
Ensenada & & & 49.5 \\
Nogales & 13.5 & 21.4 & 73.0 \\
Ciudad Juárez & 39.8 & 29.4 & 149.0 \\
Ojinaga & - & 0.8 & 6.7 \\
Piedras Negras & - & 13.3 & 32.1 \\
Matamoros & 25.5 & 7.0 & 90.0 \\
\hline
\end{tabular}

Fuente: Secretaría de la Presidencia, Inversión Pública Federal, México 1967: Comercio Exterior, noviembre 1977, p. 907 y O. Martínez op. cit..

${ }^{*}$ Estimaciones propias.

CUADRO 3

Valor de las ventas totales por industrias mexicanas registradas en Pronaf (\%)

(total de millones de pesos)

\begin{tabular}{lccccccc}
\hline & 1960 & 1961 & 1962 & 1963 & 1964 & 1965 & 1966 \\
\hline Distrito Federal & - & - & - & - & 26.92 & 37.51 & 39.29 \\
Nuevo León & - & - & - & - & 17.08 & 17.74 & 14.54 \\
Baja California & - & - & - & - & 16.53 & 13.63 & 16.83 \\
Chihuahua & - & - & - & - & 9.20 & 7.31 & 6.09 \\
Jalisco & - & - & - & - & 6.22 & 3.27 & 2.72 \\
Coahuila & - & - & - & - & 5.58 & 3.19 & 3.91 \\
Tamaulipas & - & - & - & - & 4.16 & 2.62 & 2.78 \\
Sonora & - & - & - & - & 1.70 & 1.20 & 1.52 \\
Otros & - & - & - & - & 29.13 & 12.48 & 13.83 \\
Estados fronterizos & - & - & - & - & 54.25 & 46.69 & 45.67 \\
Total & 434.0 & 593.0 & 677.0 & 1053.0 & 1201.9 & 1221.7 & 1542.7 \\
\hline
\end{tabular}

Fuente: Comercio Exterior, enero de 1966, p. 25 y 1967, p. 591. 
os de transporte. Hasta 1967 esos subsidios ascendian a 149.5 millones le pesos, de los cuales 60 millones eran subsidios por ingresos mercanties y el resto (89.5 millones) fueron descuentos de transporte. ${ }^{11}$ En lo que zoncierne a la protección contra bienes extranjeros, en 1969, 300 producos estaban sujetos a tarifas en la RFN. ${ }^{12}$ El cuadro 3 muestra el valor total ie las ventas de firmas mexicanas no fronterizas, registradas en Pronaf. uos datos muestran que la mayor parte de las firmas más beneficiadas por al programa se localizaron en el Distrito Federal, y que los estados fronte:izos redujeron su participación relativa en el mercado de la RFN. Difícilnente estos resultados muestran una mayor integración.

El otro mecanismo que era (y es) parte integral del régimen de franja ronteriza fue administrado por la Secretaría de Industria y Comercio. Este zonsistía en la autorización para importar bienes. Aquéllos que compitiean tanto con productos mexicanos como fronterizos no podrian ser imjortados. Para 1969, 750 productos estaban sujetos a licencia de importa:ión. ${ }^{13}$ La intención global del sistema de licencias e impuestos a la mportación era proteger el mercado de la RFN tanto para el productor lo:al como para el productor del resto del país. ${ }^{14}$

El programa de obras públicas fue el único instrumento bajo control lirecto del Pronaf. La construcción y financiamiento de este tipo de trabaos intentaban alentar el turismo norteamericano, el comercio y la indusria. La inversión total fue de $\mathbf{4 8 3 . 4}$ millones de pesos corrientes y estuvo Itamente concentrada. Entre 1961-1967, 64.5\% fue canalizado hacia tres :iudades: Ciudad Juárez, Matamoros y Nogales (véase cuadro 2). Alguios fondos se dirigieron a la construcción de centros comerciales, hotees, parques, tiendas de artesanías y, en general, a obras de infraestructua urbana. Sin embargo, la mayor parte del presupuesto se asignó a obras le embellecimiento urbano. ${ }^{15}$

11 Comercio Exterior, nov. de 1967, p. 907, y feb. de 1968, pp. 125-126. En 1972 la candad de impuestos sobre ingresos tansferida por el gobierno (mediante cEDts) fue de 2380 tillones de pesos.

12 Mike Farrell, "The Economy of Baja California", en Peter L. Reich, Statistical bstract of the United States Mexico Borderlands, Statistical Abstract of Latin America, Suplement 9, Latin American Center Publications, University of California, Los Angeles, 1984. .95.

13 Ibid.

14 Mendoza Berrueto, op. cit. Véase también, John W. House, Frontier of the Rio Grane: A Political Geography of Development and Social Deprivation, Clarendon Press, Oxford, 982, pp. 209-210.

15 En 1942 los gobiernos de México y Estados Unidos acordaron la creación del prograla de mano de obra mexicana que permitía a los trabajadores mexicanos ser contratados para alizar labores agrícolas en Estados Unidos. Tenfan los derechos de cualquier trabajador estaunidense. Este programa es conocido como el Programa de Braceros. Finalizó en 1947, pero I mantuvo informalmente. Se restableció formalmente en 1951 y terminó en 1964. Entre quiees ven el Programa para la Industrialización de la Frontera como una respuesta al desemleo causa do por el fin del programa de braceros, se puede mencionar a Donal W. Baerresen, he Border Industrialization Program, Lexington Books, 1973, y Mendoza Berrueto, op. cit. 
Pronaf no tuvo éxito en el sentido de haber alcanzado sus objetivos. Parte de ello puede ser atribuido a que tales objetivos eran demasiado generales. Por otro lado, considerando la estructura de su organización, sólo se concentró en las obras públicas, que además se concentraron en el elemento embellecedor más que en los aspectos propiamente económicos de esas obras.

El hecho de que el programa de franja fronteriza no haya sido eliminado junto con Pronaf en 1965, puede deberse también a su estructura administrativa: tal programa dependfa de Hacienda y no de Pronaf.

En realidad Pronaf no fue una verdadera agencia de desarrollo regional, sino que más bien fue una especie de contratista.

En lo referente al régimen de franja fronteriza no es claro cuáles fueron sus logros, al menos durante la existencia de Pronaf. El valor de los productos mexicanos vendidos en la RFN representaron $31-36 \%$ del valor total del gasto de mexicanos en Estados Unidos (medido en relación a las transacciones fronterizas). En términos generales eso era el valor del coeficiente de retención ( = ingresos - gasto/ingreso).

CUADRO 3a

Subsidios otorgados por el Pronaf

\begin{tabular}{lrrr}
\hline & $\begin{array}{c}\text { Exenciones } \\
\text { de isiM }\end{array}$ & $\begin{array}{c}\text { Devoluciones } \\
\text { sobre costos } \\
\text { de transporte }\end{array}$ & Total \\
\hline 1961 & 2.3 & 1.9 & 4.2 \\
1962 & 6.9 & 9.4 & 16.3 \\
1963 & 9.3 & 13.2 & 22.5 \\
1964 & 10.8 & 15.4 & 26.2 \\
1965 & 11.9 & 15.9 & 27.8 \\
1966 & 14.5 & 18.0 & 32.5 \\
1967 & 13.4 & 19.2 & 32.6 \\
Total & 69.1 & 93.0 & 162.1 \\
\hline
\end{tabular}

Fuente: Programa Nacional Fronterizo, en The Review of the Economic Situation of Mexico, XIV, 514, septiembre de 1968, p. 6.

4. El Programa de Industrialización Fronteriza o Programa Maquila Algunos autores consideran este programa como una respuesta directa al incremento en los niveles de desempleo en la RFN producto de la terminación, en 1964, del Programa de Braceros. ${ }^{16}$ Otros lo ven como un esfuerzo deliberado del gobierno para aprovechar la tendencia de las firmas nor-

${ }^{16}$ Mendoza Berrueto, op. cit. Véase también, John W House, Frontier on the Rio Grande: A Political Geography of Development and Social Deprivation, Clarendon Press, Oxford, 1982, pp. 209-210. 
teamericanas de disminuir sus costos de producción localizándose fuera de los Estados Unidos. ${ }^{17}$ Otros más sugieren que es parte de un proceso de internacionalización de la producción industrial. Como tal estaría fueta de la esfera de control del gobierno para que hubiese sido causado por un programa industrial. No se acepta que el desempleo haya sido un fenómeno coyuntural, resultado de la terminación del Programa de Braceros sino como una característica estructural de la economía de la RFN. ${ }^{18}$

Estas explicaciones son parcialmente ciertas. Hubo un incremento en ji desempleo durante los años sesenta pero no sólo como resultado de la erminación del Programa de Braceros. Cambios en la estructura produciva del sector agrícola fueron también un factor importante en ese increnento. La adopción del programa de maquila no fue un acto tan calculalo como podría pensarse. Después de todo, durante los cincuentas hubo Jropuestas para que se permitiera que ese tipo de plantas funcionaran en uéxico. Sin embargo fueron rechazadas por ser consideradas como medilas antinacionalistas. ${ }^{19} \mathrm{El}$ programa fue adoptado en 1965 no por ser más racionalista sino porque los niveles de desempleo, producto tanto de la erminación del Programa de Braceros como por los cambios en la estrucura agrícola de los distritos de riego localizados en la RFN (así como los :ambíos sufridos en otras áreas agrícolas del país), eran de tal magnitud jue el programa fue visto como la solución más fácil. Aunque fue aprobalo en 1965, se inició en 1967.

Por medio de este programa se permitía la importación libre de imiuestos de maquinaria, equipo y material a la franja fronteriza siempre ' cuando el producto fuese reexportado. Ningún producto de las maquiadoras podría ser vendido en México. Hasta 1971 este programa funcioó en forma aislada. Sin embargo, no se debe olvidar que el programa de 1aquiladoras coexistió con el programa de franja fronteriza utilizado por 1 Pronaf así como con otros subsidios (descuento en costos de transpor3), pero no estaban coordinados.

Entre los objetivos del programa de maquiladoras se encontraba (y se ncuentra) el de "integración". Es decir, una mayor participación de inumos mexicanos en los insumos de las maquiladoras. En 1968 había 84 lantas empleando a 12314 personas. En 1969, 108 maquiladoras empleaan 15858 trabajadores. Para 1970, 120 plantas empleaban 20327 persoas y en 1971 la cifra era de 251 y 29214 , respectivamente.

El programa de maquiladoras ha sido el que mayor interés y análisis a provocado. En el contexto del presente trabajo un análisis detallado ería redundante.

17 House, op. cit., pp. 215-218.

18 Véase José Luis Fernández Santisteban, "Un análisis de la polf́tica de industrializaón Fronteriza en el periodo 1985-1979', documento presentado en el encuentro de universidass de México y Estados Unidos sobre estudios fronterizos, La Paz, Baja California Sur, 1980.

${ }^{19}$ Mendoza Berrueto, op. cit. 


\section{Programa para la Promoción Económica de la Franja Fronteriza y Zonas Libres}

Se inició en 1971 y entró en operaciones el año siguiente. En cierta forma las razones que movieron al gobierno federal para poner en marcha este programa pueden ser un veredicto sobre los resultados de programas anteriores. Eliseo Mendoza Berrueto, entonces subsecretario de Industria y Comercio nos ofrece un listado de ellas:

a) las diferencias económicas entre la RFN y el resto del país;

b) la falta de desarrollo de las actividades comerciales en la RFN;

c) una oferta limitada de productos mexicanos no fronterizos (la razón por la que el consumidor fronterizo compra del lado norteamericano);

d) la falta de facilidades e incentivos al empresario local para producir bienes dirigidos al consumidor fronterizo;

e) la carencia de promoción a las exportaciones de la RFN;

f) las actividades agrícolas no han recibido las facilidades adecuadas que les asegure, a tiempo, una oferta competitiva de insumos, equipo y maquinaria, $y$

g) el gobierno federal no ha promovido adecuadamente el turismo. ${ }^{20}$

Para contrarrestar todas estas deficiencias el programa se fijó los objetivos listados en el cuadro 1.

Una de las innovaciones del programa fue su estructura administrativa. El programa fue integrado por una comisión intersecretarial con representantes de las principales secretarías involucradas en la RFN: Hacienda, Comercio, Agricultura y Recursos Hidráulicos. Cada año, uno de los representantes presidía la comisión. Ésta operaba a través de comités regionales de promoción económica localizados en los principales centros urbanos de la frontera; ésta fue considerada como un marco unificador de todas las actividades de las secretarías relacionadas con la RFN. La comisión intersecretarial coordinaría esas actividades en una forma homogénea considerando los principales aspectos socioeconómicos de la RFN. ${ }^{21}$ Los comités regionales para el desarrollo económico estaban integrados por un presidente, un secretario y un representante local de cada secretaría involucrada, un representante del gobierno estatal y municipal, y finalmente un representante de las distintas organizaciones de negocios locales.

Era, de alguna forma, un intento de planificación desde "abajo". Cada año se llevaron a cabo reuniones plenarias, conocidas como "reuniones de trabajo"; a la cabeza estaban el presidente de México, las respectivas secretarías, y el resto de las representantes. Hubo siete reuniones, realiza-

20 ibid, pp. 29-30.

21 Vale la pena recordar que este programa y su sucesor fueron también aplicables a la frontera sur de México, así como a las zonas libres, no sólo a la península de Baja California sino también a Quintana Roo. 
las en diferentes ciudades fronterizas, presididas por Echeverría. Mendoza Berrueto, activo organizador y participante (como subsecretario de InJustria y Comercio y presidente de la comisión), señala que el objetivo de as reuniones era analizar los problemas de la RFN, para sugerir y adoptar ioluciones finales compatibles tanto con los intereses nacionales como con os regionales. ${ }^{22}$ "La idea era incluir el más amplio número de represenantes de todos los sectores económicos así como de la frontera, con objeo de enfatizar la importancia del desarrollo económico y social de la retión". ${ }^{23}$ Los representantes exponían sus casos, quejas y soluciones: 'Con base en los asuntos, problemas, y proposiciones presentadas en las euniones nacionales, la comisión intersecretarial ajustaba sus programas $r$ adoptaba las medidas necesarias para promover las diferentes actividales en el país." "24 Era, al menos en teoría, un ambicioso experimento de llanificación "desde abajo". Sin embargo, cada secretaría mantenía el conrol de los instrumentos y acciones que le correspondían. En realidad este rograma dio especial atención a aquellos aspectos y problemas asocíalos con las actividades comerciales en la RFN. ${ }^{25}$ Los principales instrunentos de este programa fueron los siguientes: a) el programa de artícuos gancho; b) el programa de centros comerciales; c) el programa de la ndustria maquiladora; d) el programa para la promoción de la industria ocal; e) el programa para la agricultura y la ganadería, y f) el programa ara promover el turismo.

iI programa de artículos gancho

lajo este programa se permitía la libre importación de artículos que norsalmente el consumidor fronterizo compraba en los Estados Unidos. Sus bjetivos fueron incrementar y diversificar la oferta a los establecimienis comerciales de la frontera, y promover la oferta y consumo de producus mexicanos no fronterizos. El programa imponía dos condiciones: vener los artículos importados a un precio más bajo o igual al precio orteamericano, y comprar y vender productos mexicanos por la cantiad equivalente de los importados bajo el programa.

El gobierno fijaba cuotas globales para cada uno de los mayores cenos urbanos de la RFN. Estas cuotas eran administradas por los comités e promoción económica.

I programa de centros comerciales ebe ser considerado como complemento del programa de artículos ganho. Mediante este programa se intentaba promover la construcción de

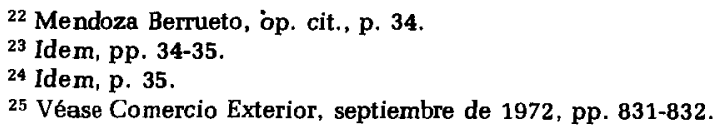


centros comerciales modernos y funcionales que pudiesen competir con los localizados del lado norteamericano. Ellos ayudarian a incrementar la venta de productos mexicanos. Dentro de este programa el gobierno federal:

a) proporcionó subsidios de $100 \%$ (hasta 10 años), sobre los impuestos a la importación de los bienes de consumo demandados por la población fronteriza y vendidos dentro de la franja fronteriza;

b) proporcionó un subsidio similar para la importación de materiales y equipo necesarios para la construcción y acondicionamiento de esos centros comerciales;

c) aceleró la depreciación de la inversión fija (edificios, equipos, etc.);

d) simplificó los procedimientos aduanales al permitir que las bodegas de las tiendas funcionaran como recintos fiscales. Todos los procedimientos aduanales se realizaban dentro de las bodegas, y

e) la comisión intersecretarial apoyó las aplicaciones de crédito de los inversionistas interesados.

Las condiciones impuestas por el gobierno fueron: que los centros comerciales rindieran $50 \%$ o más de productos mexicanos; que el capital debía ser mexicano; la inversión total tendría que sobrepasar un mínimo, y que el centro comercial debía tener un determinado tamaño.

El programa de la industria maquiladora

Era la continuación del programa que habla funcionado ininterrumpidamente desde 1965. La única modificación fue la elaboración de un reglamento que delimitaba claramente las funciones respecto de los permisos de importación de la Secretaría de Hacienda y de la de Industria y Comercio. Los comités regionales fueron autorizados para otorgar permisos temporales de importación y algunos procedimientos aduanales fueron simplificados.

El programa para promover la creación de mediana y pequeña industria Su objetivo fue promover industrias no maquiladoras. Oficialmente lo que provocó la creación de este programa fue la falta de industria no maquiladora, así como la incapacidad de la industria local para abastecer el mercado fronterizo y el poco empleo en esa clase de industria. En particular, se consideraba la RFN como una región atrasada. De acuerdo con Mendoza Berrueto, ello era causado por el limitado abasto de materias primas tanto por el aislamiento de la RFN (y falta de vínculos comerciales), como por la carencia de materia prima local susceptible de uso industrial. ${ }^{26}$

Así, en 1974 la comisión intersecretarial creó el programa, cuyo objetivo era promover la industrialización de productos agrícolas para abaste-

${ }^{26}$ Mendoza Berrueto, op. cit., p. 47. 
:er a la población local, promover las exportaciones no maquiladoras, geıerar empleo, y sustituir la importación de materias primas. El programa ionsistió en: ${ }^{27}$

a) un subsidio de $100 \%$ al impuesto federal de importación de mauinaria y equipo para ser usado para la industria en cuestión;

b) un subsidio de $60-100 \%$ sobre el impuesto a la importación de maerias primas y otros insumos, asi como del equipo de mantenimiento neesario para la industria.

Para recibir esos beneficios el gobierno imponía dos condiciones: que $00 \%$ del capital fuera mexicano y que el capital social fuera menor a inco millones de pesos.

'rograma para promover las actividades agrícolas y ganaderas u principal objetivo fue promover la mecanización de la agricultura. Paa lograrlo, el gobierno permitió la libre importación de maquinaria agriola, fertilizantes, semillas etc. Además, se incluyó una sección agrícola $\mathrm{n}$ el programa de artículos gancho. Consistió en la importación de alirentos balanceados.

'rograma para la promoción del turismo

Jingún instrumento específico fue creado para este programa. El gobiero sólo anunció que se promovería la construcción de hoteles y centros e recreación.

a1

rograma para promover la sustitución de importaciones en la RFN .l igual que el programa para promover las ventas de bienes mexicanos o fronterizos, la comisión intersecretarial aprobó la creación de un instrurento llamado certificado de devolución de impuestos (Cedis). La RFN le considerada como una zona de exportación y el gobierno aceptó otorar a los "exportadores" el impuesto federal de ingresos mercantiles asi omo todos los impuestos directos sobre aquellos productos destinados la RFN. Los impuestos les eran devueltos a los "exportadores" median3 los Cedis.

esultados del programa para la promoción económica de la RFN valuar los efectos de algún programa de desarrollo es siempre difícil, entre tras razones porque es un problema decir qué hubiera pasado de no haber xistido el programa. Sin embargo, se puede obtener una útil aproximaión comparando algunos indicadores con los objetivos del programa.

En el presente caso esta alternativa hace que surja otro problema: dado ue el programa bajo análisis no cuantifica sus objetivos, ¿cómo evaluar

\footnotetext{
${ }^{27}$ En 1976 el gobierno cancelb el sistema de subsidio e introdujo en su lugar el sistema exenciones y reducciones en los impuestos a la importación.
} 
su éxito? Una posible solución sería analizar algunas de las inconsistencias entre los resultados, en términos de algunos indicadores, y los objetivos propuestos por el programa. Ésta es la perspectiva que seguiremos en este artículo.

Uno de los objetivos del programa fue mejorar el saldo de las transacciones fronterizas (TF). Como uno de los renglones en la balanza comercial de México, siempre se han considerado las TF como una aproximación de las transacciones comerciales de la RFN con el sureste de los Estados Unidos. Este objetivo implicaría que el ingreso por TF debería crecer más rápido que el gasto. De hecho este objetivo es la piedra angular de todo el programa, la idea básica detrás de todos los otros objetivos (sustitución de importaciones, promoción de exportaciones, etc.).

En principio no hay nada criticable en este objetivo; sin embargo, utilizar el concepto de TF presenta importantes problemas metodológicos y prácticos que desde luego afectan el objetivo general.

Las TF registran todas las transacciones monetarias en la RFN. Hasta 1980 se basaban en los movimientos de moneda extranjera en el área. De acuerdo con este ingreso, sería la cantidad de pesos comprados en la RFN, y el gasto sería la compra de dólares con pesos mexicanos. Por tanto no necesariamente registra el valor de las actividades económicas llevadas a cabo estrictamente en la RFN.

Una de las características distintivas de regiones fronterizas con fuerte interacción socioeconómica es el amplio uso de aceptación de la moneda de cada uno de los respectivos países. La frontera entre México y los Estados Unidos no es la excepción. Hay una gran cantidad de mexicanos que, viviendo del lado mexicano, trabajan regularmente en los Estados Unidos. Se les paga en dólares y frecuentemente gastan en dólares. Sus actividades no son registradas como transacciones fronterizas pues sus transacciones no requieren, forzosamente, cambio de moneda.

Otro problema relacionado con las transacciones fronterizas es que, en su totalidad, la diferencia entre los ingresos y los egresos como porcentaje de los ingresos totales (el así llamado coeficiente de retención) siempre ha sido positivo, con un promedio de $40 \%$ desde 1939 (37\% para 1970-1976).

Una balanza comercial con un superávit de $37-40 \%$ difícilmente puede justificar una política hacia su mejoramiento. En otras palabras, se carece de bases objetivas para decir que un balance positivo es insuficiente. Las transacciones fronterizas no pueden considerarse entonces un indicador del desarrollo de la RFN. Un programa económico regional basado en un indicador equivocado tiene una dudosa relevancia. Sin embargo, para fines de análisis, asumamos que las TF son la aproximación confiable de la balanza comercial de la RFN. De esta forma podremos analizar un programa 
directamente encaminado a promover las actividades como un medio para mejorar dicha balanza comercial: el programa de artículos gancho.

Diseñado para mantener al consumidor fronterizo en México, se esperaría una distribución más o menos pareja, del valor total de la cuota autorizada entre las principales ciudades fronterizas. Sin embargo, Ciudad Juárez recibió casi $\mathbf{5 0 \%}$ de esa cuota. Más aún, en ningún caso se ejerció totalmente la cuota establecida de artículos gancho. Es difícil argumentar que tan alta concentración, y un uso relativamente bajo de la cuota de artículos gancho, puedan demostrar que el programa ayudó a retener al consumidor fronterizo en la RFN.

El programa de artículos gancho contenía dos categorías principales de bienes: de consumo y de producción. Los primeros estaban, además, divididos en durables y no durables. Dentro de los primeros se encontraban artículos electrónicos y eléctricos, productos de belleza, ropa, papelería, etc. Dentro de los segundos, productos agrícolas, lácteos, pollo, varios tipos de bebidas, leche en polvo, etc. De acuerdo con Mendoza Berrueto, los artículos de consumo no duradero eran prioritarios para el programa. El cuadro 4 muestra que los resultados no confirman ese propósito. En 1972, 70\% de la cuota ejercida de bienes de consumo fueron no duraderos. Para 1976 (el final teórico del programa), la situación había cambiado: $56 \%$ de la cuota ejercida por bienes de consumo era de duraderos. Para 1976 la cuota ejercida fue de $73 \%$ de duraderos contra $62 \%$ de no duraderos. Lo anterior sugiere que el programa de artículos gancho favoreció la importación de bienes que supuestamente vendrían de otras partes de México.

El hecho de que la demanda de bienes duraderos se incrementara más que la demanda de los no duraderos pudo deberse a dos factores: un incremento en el ingreso de la población fronteriza y el incremento en la demanda de tales bienes por residentes no fronterizos. La primera es una fuerte posibilidad como resultado, por ejemplo, de la industria maquiladora. La segunda también es muy posible. Para nadie es un secreto que la gente de Chihuahua compra en Ciudad Juárez-El Paso; la de Monclova compra en Acuña y Piedras Negras; la de Monterrey y Saltillo en Reynosa y Laredo.

En términos del coeficiente de retención (CR), los resultados tampoco fueron favorables al programa. El CR se mantuvo más o menos igual entre 1972 y 1976. Un análisis desagregado ofrece diferentes resultados. Ciudad Juárez, donde se asignó $\mathbf{5 0} \%$ de la cuota de artículos gancho, tuvo, en promedio, un CR de 58\% (1972-76). Agua Prieta, donde se consumió sólo $0.12 \%$ de la cuota de artículos gancho, presentó un CR de $52 \%$ durante el mismo periodo. Un resultado similar se presentó en Acuña. En estos casos no hay relación entre el valor de los artículos gancho consumidos y el CR. El caso de Ciudad Juárez no puede ser considerado como un resultado positivo porque el CR era un poco más alto antes de 1972. 


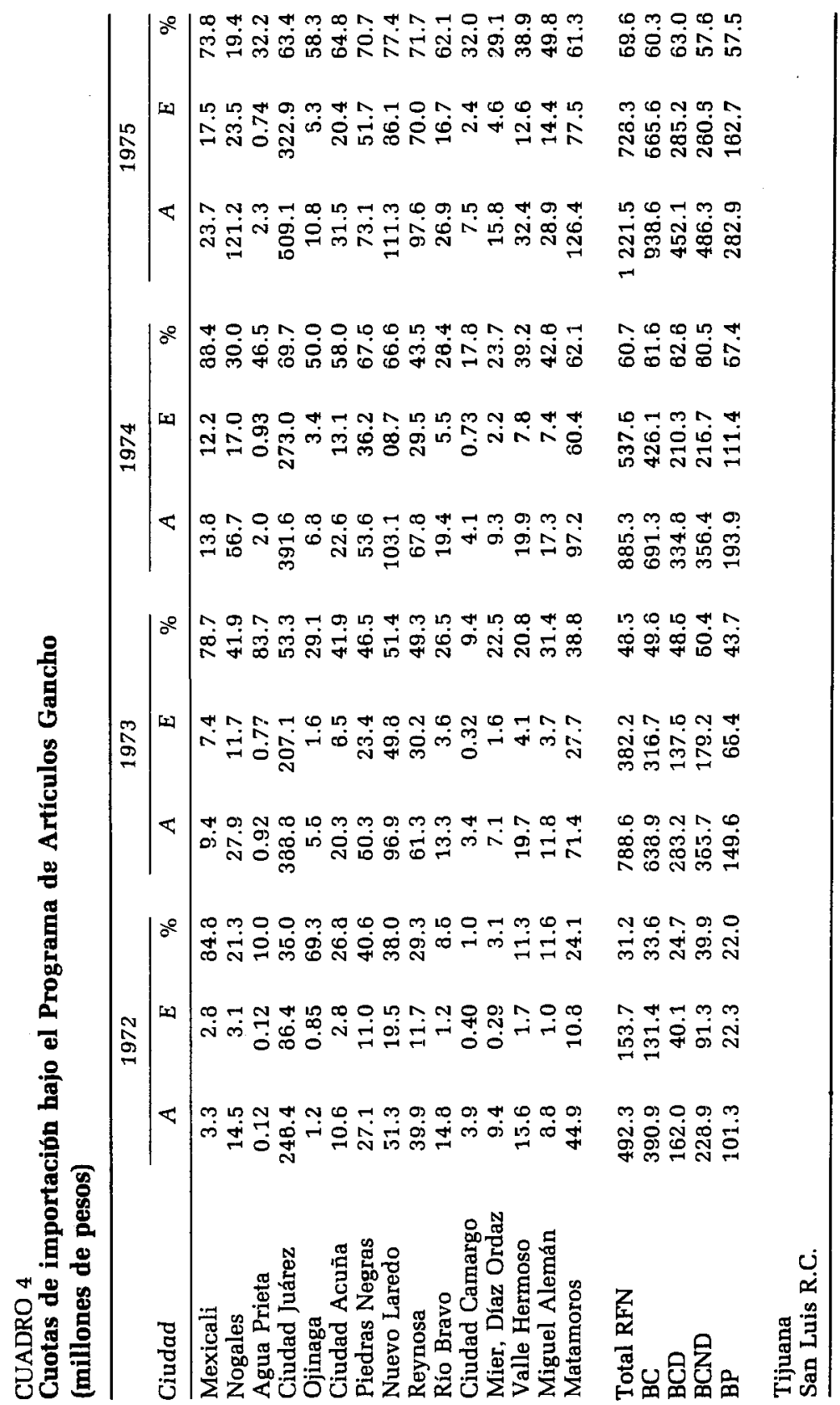




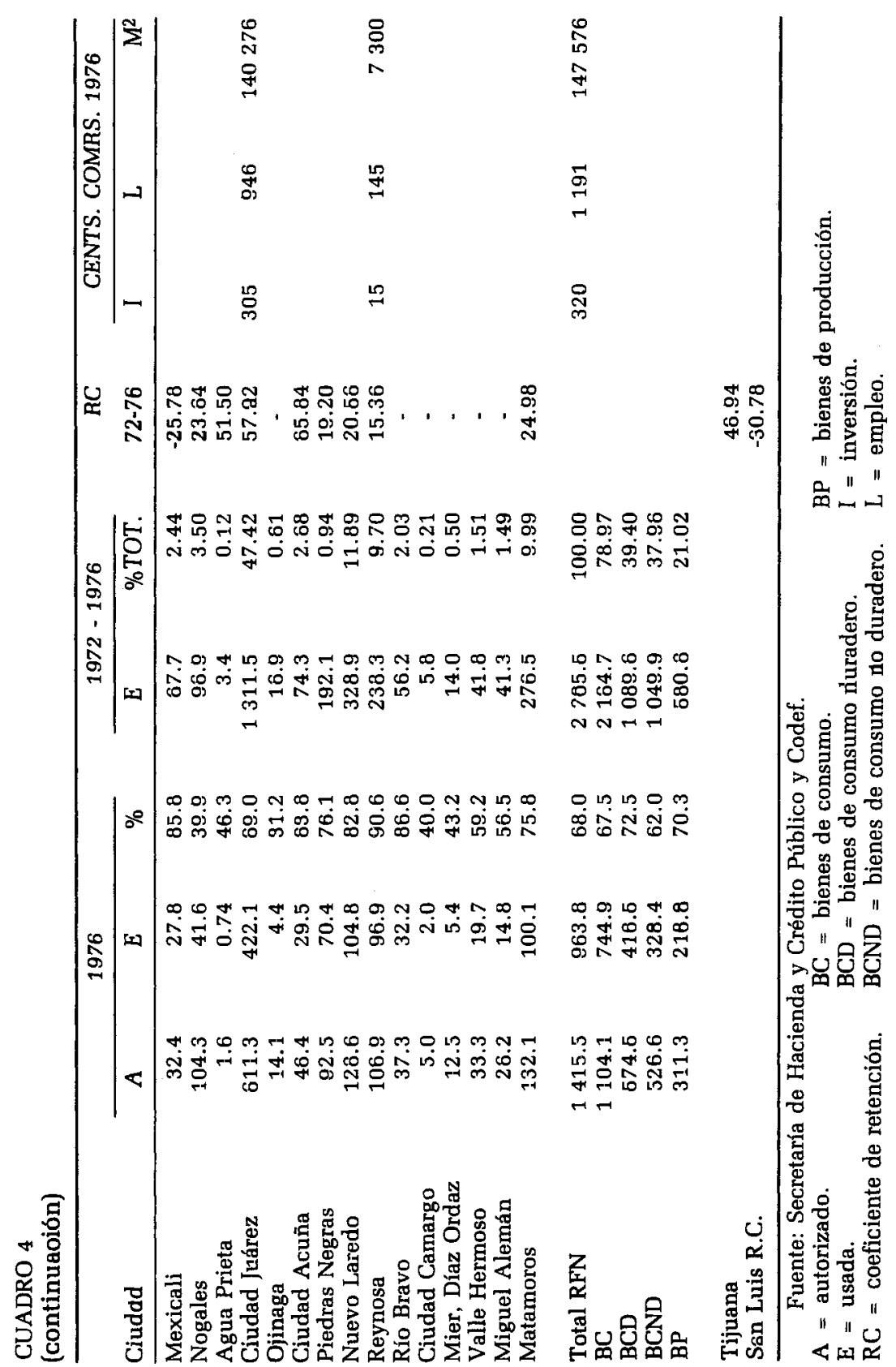


En algunos casos se podría considerar que el programa tuvo un éxito relativo. Las ciudades con los CR más bajos en 1972 eran las localizadas en Tamaulipas (Nuevo Laredo, Reynosa y Matamoros), donde lo habían aumentado a $20 \%$ promedio en 1976. Sin embargo, su participación en el consumo de artículos gancho fue bastante baja $(11,10$ y $10 \%$, respectivamente). Cualesquiera que sean sus razones, este éxito relativo queda borrado por la situación de Mexicali y San Luis Río Colorado, dos ciudades que desde 1966 mostraban CR negativos y que durante el periodo 19721976 lo tuvieron, en promedio, de $\mathbf{- 2 6}$ y $\mathbf{- 3 1 \%}$ (sólo hay datos disponibles para este periodo).

En términos de los objetivos del programa, estas dos últimas ciudades deberían haber equilibrado su balanza comercial. En consecuencia, la cantidad más alta de artículos gancho debería haberse dirigido al consumidor de estas ciudades. No hay datos sobre artículos gancho para Río Colorado, pero Mexicali sólo consumió $2.4 \%$ del valor total de esos bienes. Se podría decir que el programa no afectó a esas ciudades porque eran (y son) perímetros libres, y como tales no necesitarían artículos gancho. Sin embargo, Tijuana, que también es perímetro libre, tuvo un CR de $47 \%$.

Vale la pena analizar este caso con mayor profundidad. Se ha especulado sobre la naturaleza de los patrones de importación y consumo de la RFN. Esta especulación se debe, principalmente, a la carencia de información sobre la frontera. No obstante, el área de Baja California ha sido objeto de varias investigaciones. Dado que son perímetros libres, el gobierno también proporciona alguna información sobre importaciones.

En 1962 el Banco de México llevó a cabo un investigación sobre el gasto de consumo mensual de la población de Tijuana y Mexicali. Los resultados, resumidos y anualizados, se muestran en el cuadro 5. Este cuadro también sintetiza los resultados de otra investigación realizada por el Comité para el Desarrollo Económico de la Península de Baja California en 1968. Aunque esos estudios no son comparables, muestran una asombrosa consistencia. En 1962 ambas ciudades gastaron 2401.2 millones de pesos en consumo; $\mathbf{4 0} \%$ de ese gasto se dirigió a alimentos, bebidas y tabaco. Los bienes importados totalizaron 1294.8 millones de pesos, casi $54 \%$ del gasto total. Alimentos y bebidas importados ascendieron a 604.8 millones de pesos o $47 \%$ del gasto en consumo de bienes importados. Más importante aún es el hecho de que $63 \%$ del total consumido en alimentos y bebidas era importado. Ambas ciudades mostraron patrones similares de consumo, con excepción del ramo de químicos y farmacéuticos.

Las elevadas cantidades que se gastaron en Mexicali en este tipo de bienes se debieron a que es un importante centro agrícola y ganadero. Es difícil decir algo sobre la clase de bienes importados, pero el estudio de 1968 nos permitirá elaborar este punto. El estudio sólo comprendió Mexicali, pero de acuerdo con el patrón de importaciones y consumo mencionados, es posible, con alguna justificación, hacer extrapolaciones para Ti- 


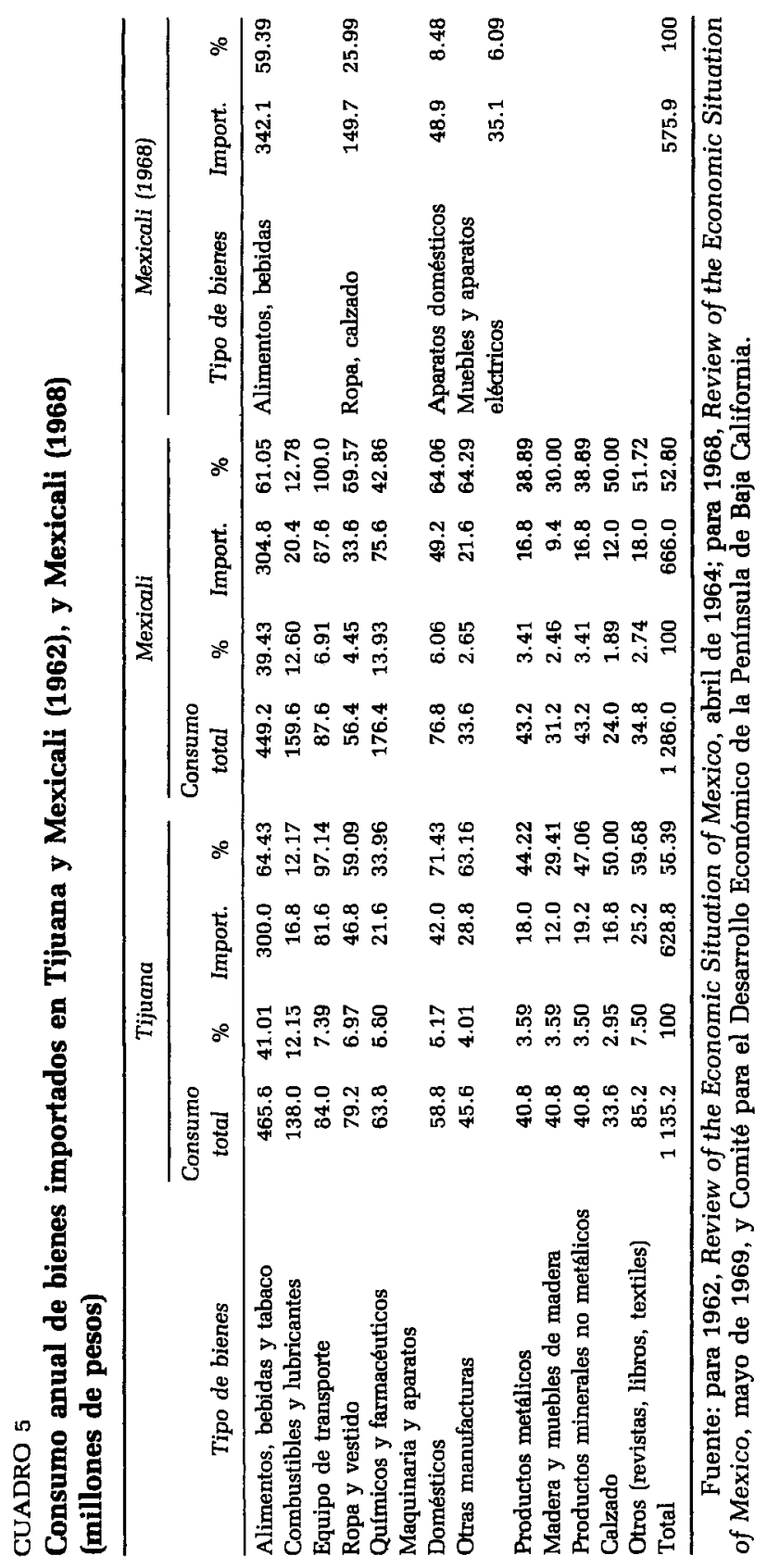


juana. Alimentos y bebidas fueron, nuevamente, los mayores bienes importados: 342.1 millones de pesos, o $60 \%$ del total importado. Este estudio encontró que casi $\mathbf{8 0} \%$ de la población iba a hacer sus compras a Caléxico. Además, la mayoría hacía ahí sus compras semanales. ${ }^{28} \mathrm{El}$ cuadro 6 muestra que los mayores bienes importados por los habitantes de Mexicali eran: huevos, manteca, leche, frijoles, pan y carne. En la mayoría de los casos se ofrecían en Caléxico esos alimentos a precios más bajos que en Mexicali. Las únicas excepciones fueron leche fresca, ternera, arroz, azúcar y limones, que si se compraban en los Estados Unidos, era porque probablemente no habia suficiente oferta. Esto se confirma por la razones expresadas por los consumidores que compraban en Caléxico. El cuadro 6 muestra que $88 \%$ compraba en esa ciudad debido a los precios bajos. Esto da un indicio sobre la naturaleza de una política regional encaminada a promover las actividades comerciales mediante centros comerciales y artículos gancho, cuando la mayor ventaja es en realidad los precios de los negocios de la frontera estadunidense. Estos centros comerciales y tiendas son, en general, parte de fuertes cadenas estadunidenses. Sus intereses comerciales y operaciones no se restringen a la frontera estadunidense. Como resultado de la gran escala de sus operaciones tienden a ofrecer mercancía a precios mas bajos y no es tan fácil hacerles competencia. Si la idea de los centros comerciales en el lado mexicano era alentar a los inversionistas individuales y propietarios de pequeñas cadenas comerciales para que invirtieran y compitieran con cadenas estadunidenses como Safeway, Walgree, K. Mart, J.C. Penny, Woolco, Gibson, etc., entonces el programa fue un fracaso desde el principio.

Más aún, estas grandes y poderosas cadenas tienen costos financieros más bajos y acceso más fácil al crédito que pequeños inversionistas. ${ }^{29}$ Ello no indica que no haya grandes tiendas y centros comerciales en las ciudades fronterizas, pero se debe tomar en cuenta que su área de mercado no se reduce a esas ciudades. El contrabando y las compras por consumidores no fronterizos son hechos comunes y ampliamente conocidos (aunque no bien documentados). Los intentos oficiales por retener al consumidor fronterizo mediante la construcción de centros comerciales, sin atender a la estructura comercial de las cadenas estadunidenses fue, y aún es, un objetivo altamente irreal.

El análisis de las importaciones de Tijuana y Mexicali como perímetros libres, muestra también algunas características interesantes. A pesar de la escasa información, el cuadro 7 muestra que el valor total de sus importaciones durante el periodo 1962-1969 fue equivalente a $34 \%$ del total de las transacciones fronterizas, o $36 \%$ si incluimos los otros perímetros

28 Véase Comercio Exterior, "El desaffo fronterizo", 1968.

29 Consultores Internacionales S. C., Diagnóstico de la Franja Fronteriza y Zonas Libres en México, preparado para la Concanaco, México, 1979. 
CUADRO 6

Méxicali: principales alimentos comprados por la población de Mexicali en Caléxico (Estados Unidos)

1968

\begin{tabular}{lcc}
\hline \multicolumn{1}{c}{ Producto } & $\begin{array}{c}\text { Valor } \\
\text { (millones de pesos) }\end{array}$ & $\begin{array}{c}\text { Indice de precios al } \\
\text { menudeo en Mexicali } \\
\text { comparado con el de } \\
\text { Caléxico (Caléxico =100) }\end{array}$ \\
\hline Huevo & 17.5 & 168 \\
Pollo fresco & 5.8 & 147 \\
Frijol & 9.8 & 125 \\
Manteca & 15.6 & 117 \\
Leche fresca & 7.0 & 79 \\
Carne de puerco fresca & 6.9 & 121 \\
Ternera fresca & 4.8 & 88 \\
Carnero fresco & 3.2 & - \\
Pan rebanado & 1.5 & 111 \\
Aceite & 1.3 & 140 \\
Avena & 11.6 & 114 \\
Leche evaporada & 3.0 & 100 \\
Café en grano & 2.2 & - \\
Arroz & 2.6 & 738 \\
Azúcar & 0.9 & 53 \\
Limón & 1.5 & 48 \\
Naranja & 1.9 & 104 \\
Pescado y mariscos & 0.2 & - \\
Plátano & 1.5 & 128 \\
Papa & 1.9 & 144 \\
\hline
\end{tabular}

Fuente: Comité para el Desarrollo Económico de la Península de Baja California y Review of the Economic Situation of Mexico, mayo de 1969.

\section{CUADRO 6a}

Mexicali: razones para comprar en el lado estadunidense de la frontera

\begin{tabular}{lc}
\hline \multicolumn{1}{c}{ Razones } & \% que dijo "sf" \\
\hline Precios más bajos & 88.1 \\
Mejor calidad & 70.2 \\
Amplios centros comerciales & 52.6 \\
Higiene, empaque y presentación & 46.2 \\
Facilidades de crédito & 34.1 \\
Mejor atención & 30.6 \\
Mayor variedad de productos & 25.4 \\
Hábito & 23.4 \\
Novedad & 19.7 \\
\hline
\end{tabular}

Fuente: Ibid. 


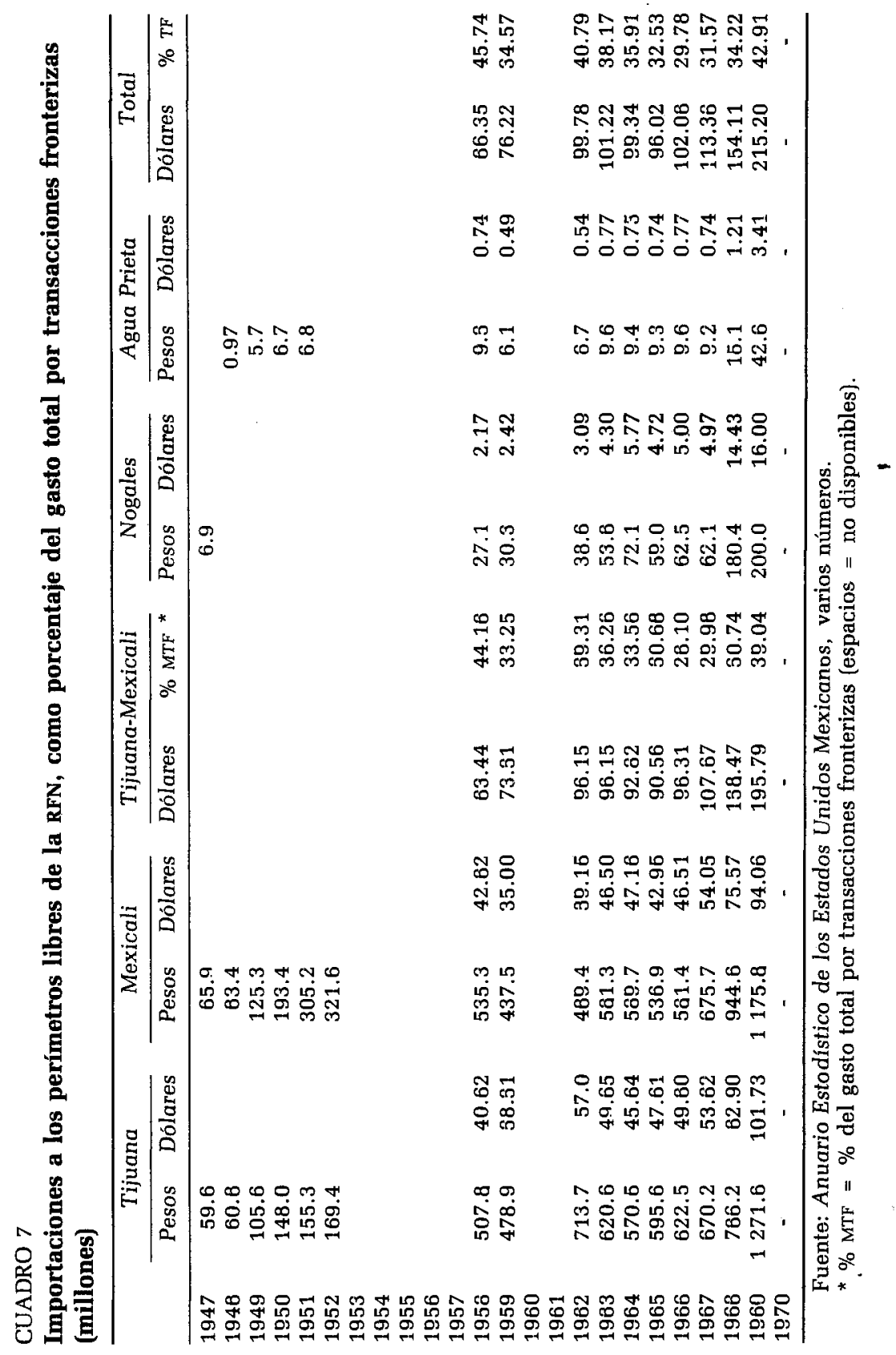


libres de la RFN: Nogales y Agua Prieta. Probablemente, la abolición de esos perímetros libres hubiese sido un objetivo más realista para "mejorar" las transacciones fronterizas. Dado el alto porcentaje de alimentos de esta zona, donde se ubica uno de los distritos de riego más grandes e importantes del país (Río Colorado), hubiese sido más adecuado promover un cambio en la estructura productiva de la agricultura (que durante estas épocas estaba especializada en el algodón de exportación). Pero si algo ha caracterizado a los programas regionales para la RFN, ha sido su falta de interés por las actividades primarias, a pesar de que la RFN, que en 1978, por ejemplo, contaba con $20 \%$ de toda el área irrigada nacional, era una región netamente importadora de alimentos, lo que representa algo así como 40-50\% del gasto de consumo total de la población fronteriza.

Si tomamos en consideración los datos sobre transacciones fronterizas es posible encontrar un elemento que de otra forma no es muy claro, y que subyace en la idea de lograr el balance en dichas transacciones. En el cuadro 8 vemos que el CR ha fluctuado entre 30 y $40 \%$ desde 1939 , y tuvo un promedio de $36.4 \%$ durante el periodo 1970-1976. El programa, pues, no produjo un efecto positivo en el CR. También se muestra que las transacciones fronterizas han sido un renglón importante en la balanza comercial de México. En términos de las exportaciones, ha representado $25-30 \%$ del total de exportaciones mexicanas y solamente $10-15 \%$ de las importaciones. De 1970 en adelante las transacciones fronterizas redujeron su participación en las exportaciones de 30 a $18 \%$, pero también redujeron su participación en las importaciones. El equilibrio o mejoramiento in las transacciones, por lo tanto, debe ser visto no dentro del contexto regional, sino del nacional. De esta forma, tal objetivo puede traducirse zomo un incremento de las exportaciones fronterizas en las exportacioaes de México. En el mismo cuadro se muestra que la cuenta corriente iesde 1939 ha tenido una tendencia deficitaria. Esto es particularmente :ierto desde 1950. Las transacciones fronterizas, por su parte, siempre han enido un saldo positivo y han contribuido, en forma significativa, para :vitar un mayor déficit en la cuenta corriente de México. En otras palaras, históricamente ha habido una transferencia de recursos de la RFN zacia otras regiones cuyas balanzas comerciales han sido deficitarias. La IFN ha financiado, efectivamente, las importaciones de otras regiones de México. En estas circunstancias, una política encaminada hacia el mejoamiento de las transacciones fronterizas es una forma velada de increnentar la transferencia de recursos de la RFN y financiar las importaciotes de otras regiones del país.

Este caso nos presenta una paradoja sorprendente. Hemos visto que a población de la RFN gasta aproximadamente $40 \%$ de su ingreso en bietes de consumo adquiridos en el lado estadunidense. El CR que generalaente se asume que se gasta en la RFN muestra que más bien ha sido transarido a otras regiones para financiar sus importaciones. Como resultado 


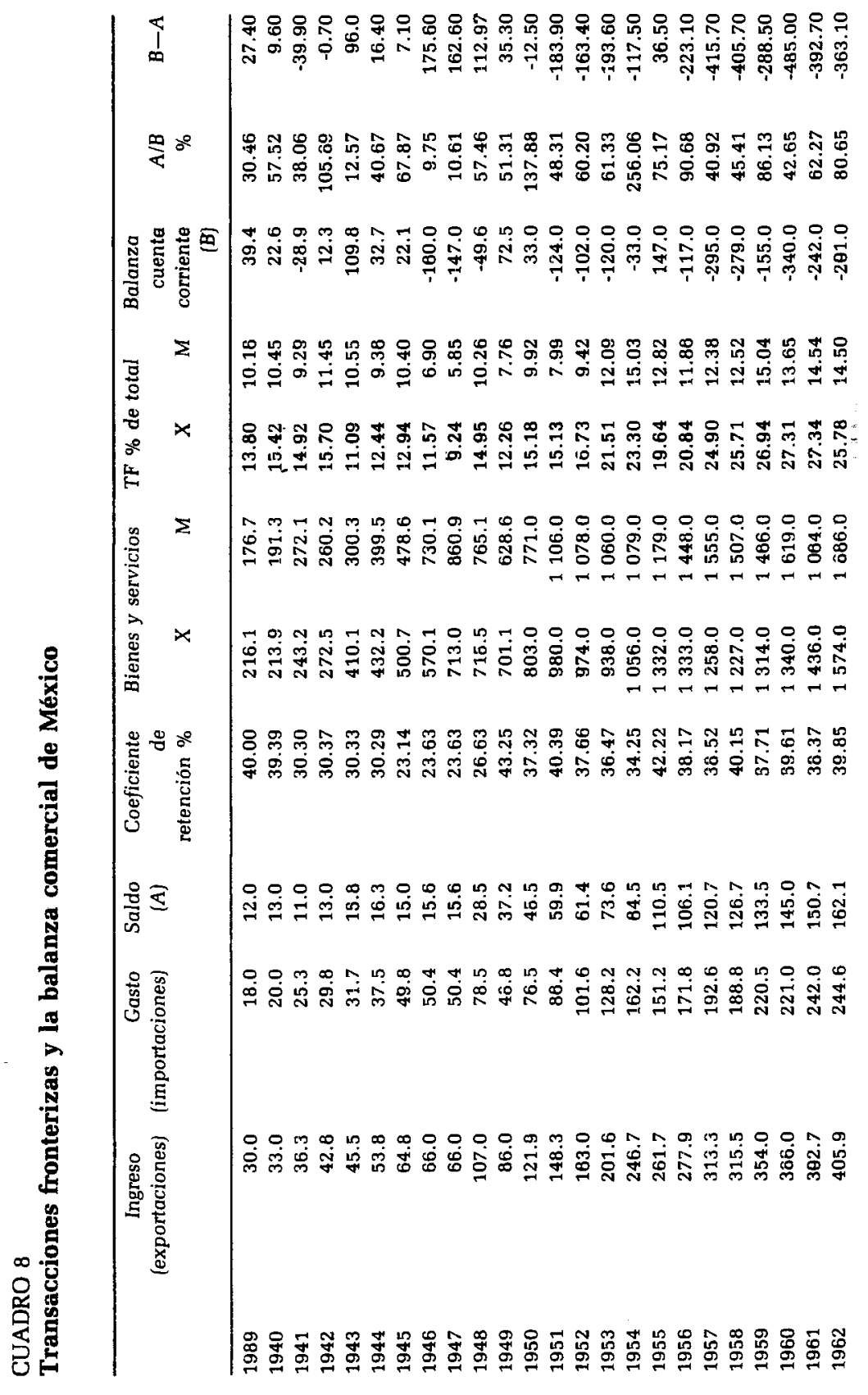




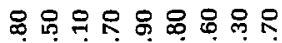

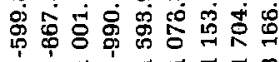

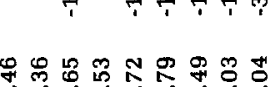

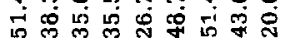

$00000+100$

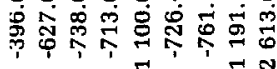

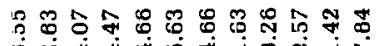

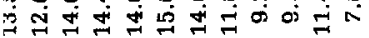

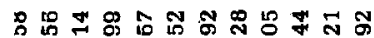

ำ

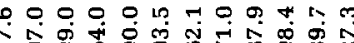

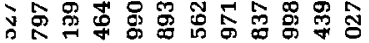

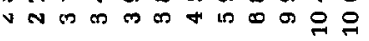

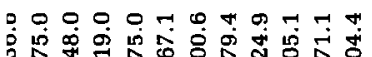

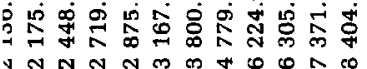

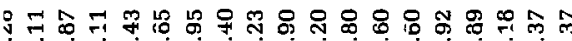

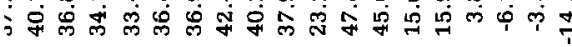


de esta doble extracción no es sorprendente que hayan fracasado los intentos por promover la industrialización vía inversión local. Quizás hubiese sido más efectivo un programa para retener ese excedente generado en la RFN que un programa para mejorar el balance por transacciones fronterizas.

Otro problema asociado con este punto se refiere a la diferencia, si es que la hay, entre vender artículos importados en el propio pais o región, o acudir al país productor y adquirirlos ahí. En teoría, la diferencia y el beneficio económico de adoptar el primer esquema serían los efectos multiplicadores locales, en términos de empleo local. Si queremos evaluar tales efectos considerando el nivel de empleo generado por el programa de centros comerciales, el resultado sería calificado como insuficiente. En el cuadro 4 se muestra que de 1974 a 1976 se invirtieron 320 millones de pesos en tres grandes proyectos. Esa enorme inversión sólo creó 1191 empleos directos. Si el programa fue concebido con la idea de una urgente necesidad local por centros comerciales, los resultados son también pobres. Durante este periodo solamente tres centros fueron construidos: los dos más grandes en Ciudad Juárez y otro en Laredo. Tales hechos apoyan nuestro argumento de que el patrón de consumo de la población fronteriza va más allá del simple hecho de una demanda local potencialmente enorme pero mal abastecida, una demanda local en espera de centros comerciales. En realidad ese patrón de consumo está asociado con la estructura local de producción, de la cual el sector agrícola es una sección importante, y con la relación entre la RFN y otras regiones de México.

Por su parte, el programa para promover la creación de industrias medianas y pequeñas tampoco tuvo resultados alentadores. Como se mencionó, el programa se inició en 1974 y continuó hasta 1978. Ese año, bajo una diferente administración, se le cambió el nombre (los detalles se darán dentro del análisis de Codef). Durante este periodo se establecieron 184 firmas acogidas bajo el decreto que aprobó el programa, creando 5000 nuevos empleos.

Quizá no sea adecuado comparar este dato con el correspondiente a las estimaciones de desempleo en la RFN, pero en las circunstancias no parece haber una mejor alternativa. Los empleos nuevos representaron $17 \%$ del desempleo según los censos de 1970 , y sólo $2 \%$ de los empleos creados por la industria maquiladora.

En lo que a salarios se refiere, parece que los trabajadores de esas industrias ganaban un salario mayor al promedio pagado por las maquilas. En 1974, por ejemplo, el salario medio mensual en la maquila era de 1484 pesos, mientras que en las plantas del programa en cuestión era de 1845 pesos.

De los datos disponibles y que aparecen en el cuadro 9 parece ser que para 1978 las empresas bajo el programa estaban pagando salarios más ele- 


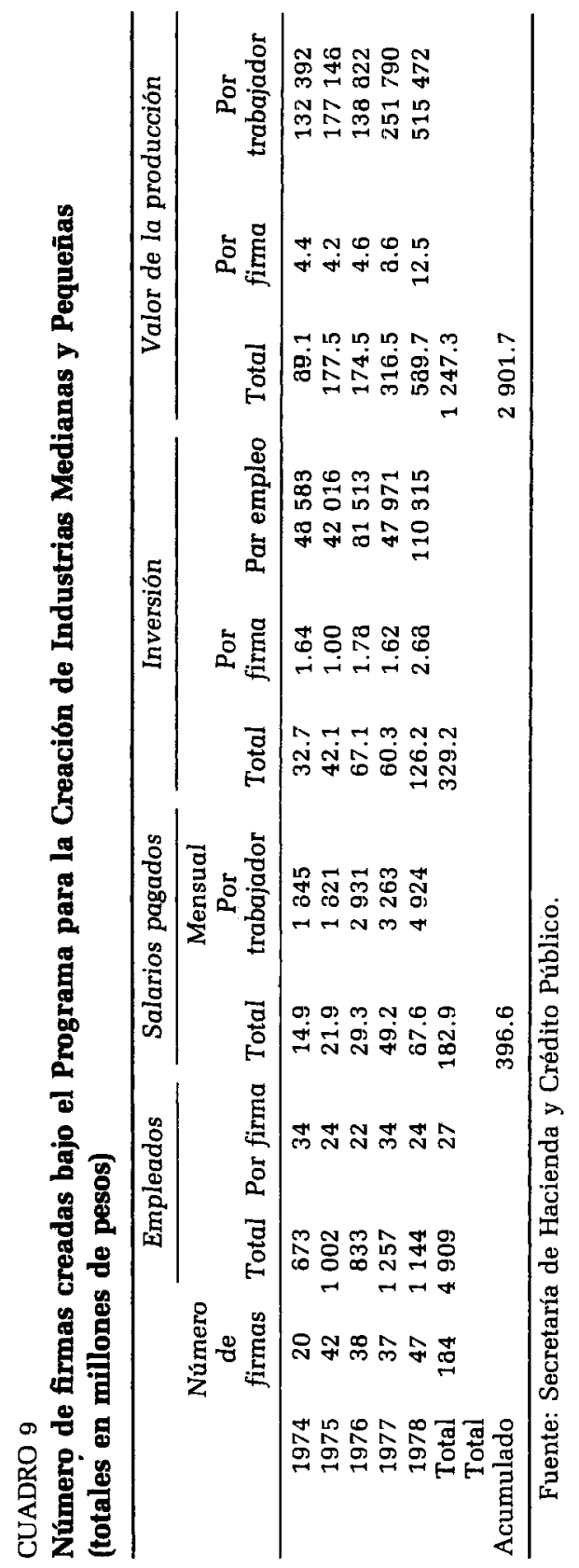


vados, requerían mayor inversión y su producto tenía un mayor valor de producción.

Quizá la mayor crítica a estos resultados proviene de su localización y distribución. Suponiendo una distribución uniforme del empleo generado entre las seis ciudades principales de la RFN, tenemos que en cinco años en cada ciudad se crearon 800 nuevos empleos. Esto reduce el efecto de todo el programa. La situación empeora si, como es de esperar, el empleo no se distribuyó uniformemente.

Al final de cuentas se puede decir que los resultados de este programa son mejores que los obtenidos por el de centros comerciales. Una cifra similar de inversión creó, en promedio, cinco veces más nuevos empleos.

Los comentarios de la industria maquiladora se han dejado hasta el final del documento porque ha sido el único programa continuo desde 1965 y por tanto no es exclusivo de Prodef. El resto de los programas fueron tan marginales que no merecen comentario alguno.

Finalmente, es importante decir algo sobre la estructura organizativa de Prodef. Como se mencionó, el programa era, en teoría, un intento por promover el desarrollo regional desde abajo. Pero su misma estructura revela un proceso altamente concentrado en la toma de decisiones. Las secretarías involucradas no delegaron ninguno de sus instrumentos. De hecho hubo una especie de doble estructura. Por un lado, estaba el sector que efectivamente tomaba las decisiones, integrado por las secretarías y sus mecanismos internos. Por otra parte, estaba el sector menos efectivo, representado por la comisión intersecretarial. Los comités regionales eran sólo oficinas locales de licencias para permisos de importación. Dado que la presidencia de la comisión intersecretarial era alternada, cada secretaría, en su momento, daba énfasis a aquellos problemas relacionados con su ramo particular. Asi, por ejemplo, cuando Mendoza Berrueto fue presidente de la comisión, como representante de la Secretaría de Industria y Comercio, dio prioridad a las actividades comerciales. ${ }^{30}$ Las reuniones de trabajo para el desarrollo fronterizo, concebidas como el foro anual donde los diversos sectores concertarían acciones efectivas, se convirtieron en meros reportes de actividades. Debido a que eran presididas por el presidente de la república, cada orador tendía a aprovechar la oportunidad para destacar personalmente y no para presentar problemas y soluciones alternativas. Su efectividad puede juzgarse por el número de oradores que tomaban parte en las reuniones. En la quinta reunión participaron más de $30{ }^{31} \mathrm{Al}$ final, las reuniones se convirtieron en asambleas anuales donde cada encargado de alguna responsabilidad gubernamental en

${ }^{30}$ Véase el "Reporte sobre la tercera reunión para el desarrollo fronterizo", en Comercio Exterior, septiembre de 1972, p. 831.

31 "V Reunión de Trabajo sobre Desarrollo Fronterizo", Comercio Exterior, julio de 1973, pp. 618-619. 
la frontera presentaba su informe de actividades. Como siempre ocurre, cada cual trataba de destacar sus logros independientemente de su importancia y validez. ${ }^{32}$

6. La Comisión Coordinadora del Programa Nacional para el Desarrollo de la Franja Fronteriza y Zonas Libres (1977-1982)

Los objetivos y las razones que se dieron para la creación de la Comisión Nacional para el Desarrollo de la Franja Fronteriza y Zonas Libres (Codef) y su Comisión Coordinadora fueron:

Para promover el desarrollo ecónomico de las franjas fronterizas y zonas libres de la República Mexicana y proporcionar soluciones adecuadas a los problemas particulares de esas áreas, el titular del Ejecutivo Federal ordenó la elaboración de un programa nacional coherente que garantice la coordinación de su ejecución y la intensificación de las acciones llevadas a cabo por el gobierno federal en sus fronteras, y en cuya concepción deberán tomar parte todas aquellas dependencias y entidades que directa o indirectamente tienen que intervenir en la atención y solución de los problemas existentes en esas regiones. ${ }^{33}$

Codef era el secretariado de la comisión nacional, cuyo objetivo prinsipal era la elaboración del Programa Nacional para el Desarrollo de las Franjas Fronterizas y Zonas Libres (Pronadef).

Este nuevo intento federal por realizar un programa de desarrollo rejional para la frontera introdujo algunas modificaciones con respecto a os intentos anteriores. Se debe notar primero el énfasis en su carácter nasional. Esto significaba que Pronadef tenía que dar un sentido de unidad il conjunto de acciones llevadas a cabo por el gobierno federal en las rejiones fronterizas de México, dentro del marco del Plan Global de Desarollo. Una segunda modificación intentaba ser una mejora respecto a la rganización de los programas previos. Para darle importancia política la omision fue presidida por el secretario de Programación y Presupuesto. .os representantes de las diferentes secretarías fueron los respectivos subiecretarios y la comisión coordinadora dependía directamente de la Se:retaría de Programación y Presupuesto (spp).

${ }^{32}$ El ejemplo más sobresaliente se encuentra en el "Informe sobre la sexta reunión para 1 desarrollo fronterizo", en Comercio Exterior, julio de 1974, pp. 683-688. En este informe paree que todas las actividades son relevantes para el desarrollo regional. Desde las acciones prolias de los programas en discusión, pasando por veinte programas para la industrialización ural, hasta programas de entrenamiento sobre el uso de básculas por Conasupo.

33 "Decreto por el que se crea la Comisión Nacional de Desarrollo de las Franjas Fronteizas y Zonas Libres y la Coordinación General del Programa Nacional de Desarrollo de las 'ranjas Fronterizas y Zonas Libres', Diario Oficial, junio 22, 1977, considerandos I, II. 
El funcionamiento de la estructura organizacional introdujo una tercera innovación. Codef tenía que producir un diagnóstico socioeconómico y formular con base en él un programa para el desarrollo de las franjas fronterizas y zonas libres. El secretariado técnico de la comisión coordinadora tenía que realizar directamente todos los estudios e investigaciones necesarios, así como otras actividades en apoyo de Codef. Así, dentro de Codef había una especie de acuerdo sobre los problemas básicos que debían ser estudiados y sobre el tipo de investigación y orientación.

La comisión coordinadora pidió a cada uno de los miembros de Codef todos los elementos necesarios para integrar tanto el diagnóstico como el programa mismo que estaban a su cargo. La respuesta de los miembros de Codef fue lenta y desigual, y muchos de los trabajos prometidos nunca se realizaron.

La idea básica dentro de la organización de Codef era que cada secretaría proporcionara una especie de diagnóstico sectorial, y la comisión coordinadora los unificaría y luego elaboraría el programa. El programa resultante se negociaría entre los miembros de Codef, quienes proporcionarian un marco general y unificado para la acción del gobierno mexicano en las fronteras. El diagnóstico fue realizado por la comisión coordinadora y fue considerado como una propuesta de SPP. Las negociaciones fueron intensas e incluso hubo oposición directa entre SPP y SAHOP, las dos secretarías relacionadas con la planificación económica y la planeación urbana. El programa fue aprobado en 1981, un año antes de que terminara el sexenio de López Portillo y cuatro y medio después de la creación de Codef. Poco o ningún efecto pudo tener dicho programa.

Sin embargo, esto no significa que la acción gubernamental en las fronteras no haya existido, especialmente en la RFN. Codef centró sus acciones en los programas e instrumentos que aún existían y que eran producto de programas previos. El control de los instrumentos estaba, como siempre, en manos de los secretarios responsables. Independientemente de Codef, cada secretaría estaba haciendo su "parte" para promover el desarrollo económico de la RFN. El programa de artículos gancho se mantuvo, al igual que el de centros comerciales. El Programa para la Promoción de la Mediana y Pequeña Industria cambió su nombre por el de Programa para la Promoción Industrial. Los incentivos fiscales fueron extendidos prácticamente a toda la industria no maquiladora. Sus objetivos principales también se mantuvieron. Durante este periodo (1977-1982) se introdujeron dos nuevos e importantes instrumentos: incentivos fiscales al turismo, e importación libre de autos y camiones. El primero se introdujo en 1979 y para su aplicación la SHCP dividió la RFN en regiones de prioridad turística. Los inversionistas en el ramo del turismo en las regiones prioritarias tenían derecho a devolución de impuestos así como a una depreciación acelerada de activos fijos. 
Resultados del programa

No es posible decir que haya habido un programa en el estricto sentido del término. Cuando fue creada Codef en 1977, desaparecieron la burocracia y los nexos de Prodef. Sin embargo, los instrumentos usados por Prodef se mantuvieron sin cambio. En las políticas hacia la RFN, el análisis de esos instrumentos presentado en la sección anterior se mantiene. Las tendencias delineadas de los artículos gancho se reforzaron (cuadro 10). Los artículos de consumo duradero incrementaron su importancia, con excepción de 1977, cuando el consumo de lơs no duraderos fue mayor que el de los duraderos. La devaluación de 1976 tuvo efectos catastróficos en ambos lados de la frontera. El consumo de básicos fue el menos afectado durante la crisis; el consumidor primero reduce el consumo de bienes duraderos. Así, mientras en 1976 el valor de los no duraderos consumidos ascendió a 320 millones de pesos, en 1977 se incrementó a 535 millones de pesos. El consumo de bienes duraderos, por el contrario, se mantuvo relativamente estable (medido en precios de 1954, el consumo de los no duraderos se increment6 $15 \%$, mientras que el de los duraderos decreció $26 \%$ ). El consumo de los artículos gancho estaba doblemente concentrado. Ciudad Juárez concentraba $\mathbf{5 0} \%$ de su consumo y en 1979 sólo 4.6\% de los establecimientos comerciales de la RFN usaban las cuotas de artículos gancho.

Durante el periodo 1972-1980, el programa de centros comerciales zeneró una gran inversión: 1050 millones de pesos y 3656 nuevos emplezs. No ofreció, pues, una solución para el problema del desempleo. Tamjoco ayudó a cambiar los patrones de consumo de la población fronteriza ver cuadro 11). Aún se carece de investigaciones en esta área, pero un sstudio realizado por Conasupo estimó que en 1979, la participación de sta agencia en el gasto total de la población fronteriza en alimentos y 'estido fue de sólo $2.8 \%$ (cuadro 12). Dado su carácter de agencia guberlamental, se puede presumir que sus ventas son una buena aproximación 1 grado de participación de los bienes mexicanos en el gasto total de conumo en alimentos y vestido de la población de la RFN.

Al parecer el Programa de Promoción Industrial fue el que tuvo meJres resultados. Al reducir los límites fijados por su antecesor (el Prograla para la Creación de Industrias Medianas y Pequeñas) respecto al taraño de la industria no maquiladora, un mayor número de firmas provecharon los incentivos fiscales proporcionados por el programa. lurante 1979 y 1980,86 nuevas firmas se establecieron en la RFN; $29 \%$ e ellos en Ciudad Juárez. Esas firmas generaron 3915 nuevos empleos :6\% en Ciudad Juárez) y un valor agregado de 803 millones de pesos. e acuerdo con la información del cuadro 13, parece que esas nuevas inustrias tuvieron un grado mayor de integración con la economía mexima. Esto parecería otorgar algo de apoyo y sentido de éxito al objetivo 


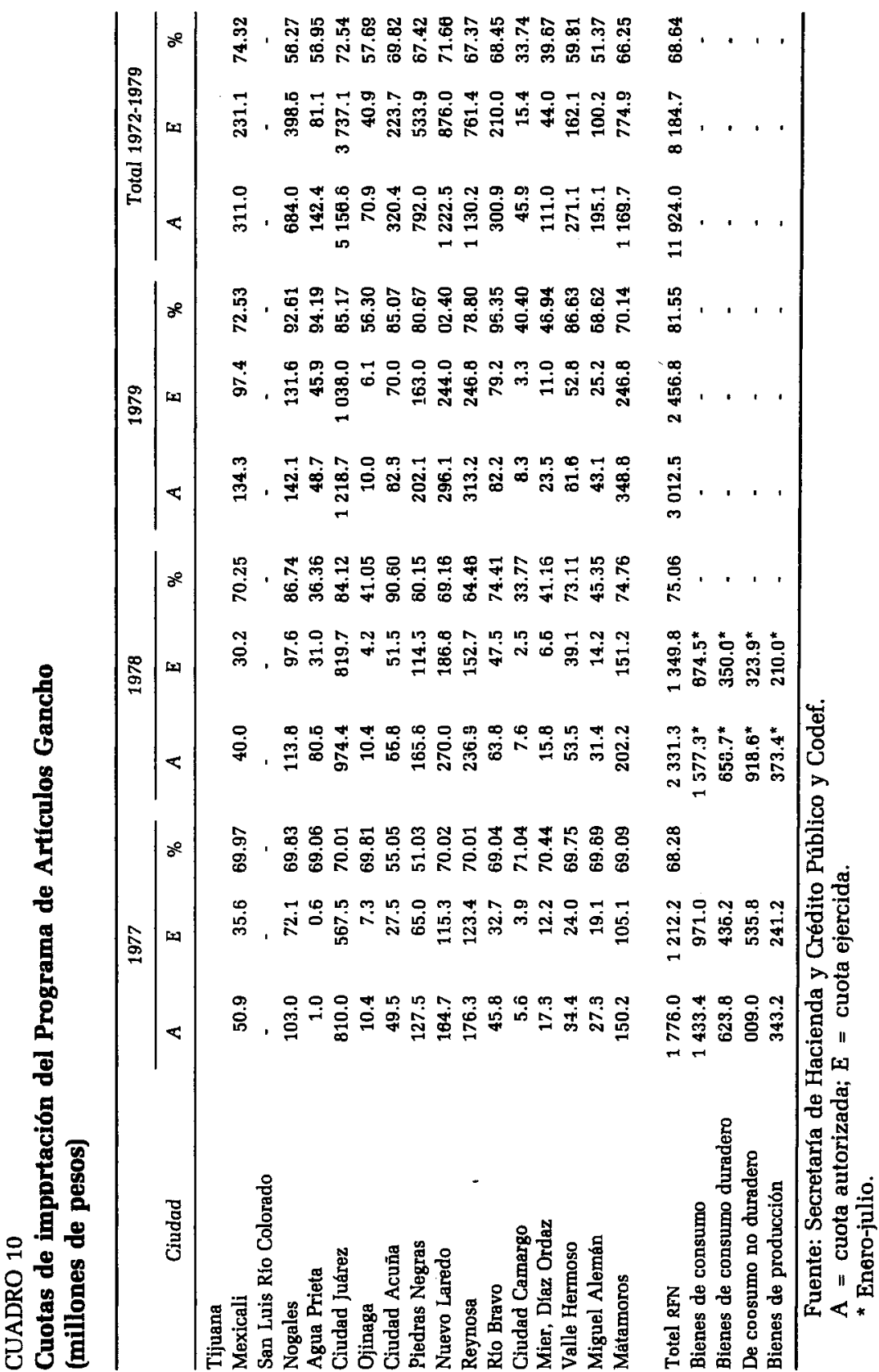




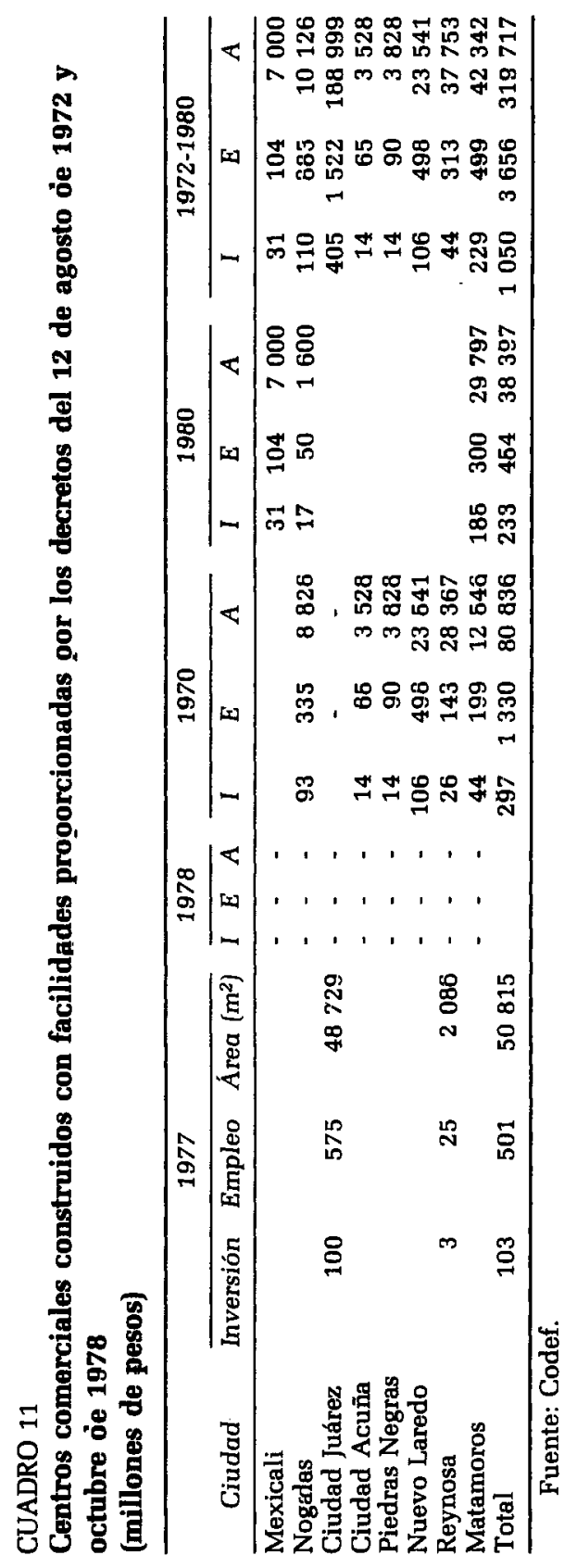


CUADRO 12

Gasto total en alimento y vestido en la RFN y participación de productos de origen mexicano vendidos por Diconsa (1979)

(millones de pesos)

\begin{tabular}{lrr}
\hline \multicolumn{1}{c}{ Ciudad } & Gasto en alimento y vestido & \% vendido por Diconsa \\
\hline Tijuana & 5951.8 & 4.6 \\
Tecate & 157.7 & 5.4 \\
Mexicali & 416.2 & 7.2 \\
San Luis Río Colorado & 366.3 & 9.1 \\
Nogales & 340.1 & 1.1 \\
Agua Prieta & 136.0 & 5.9 \\
Puerto Peñasco & 67.9 & 0 \\
Naco & 16.3 & 7.4 \\
Sonoyta & 20.6 & 8.8 \\
Ciudad Juárez & 666.4 & 0.3 \\
Ojinaga & 77.8 & 3.3 \\
Zaragoza & 20.3 & 5.3 \\
Ciudad Acuña & 214.1 & 0 \\
Piedras Negras & 242.9 & 4.0 \\
Nuevo Laredo & 2390.6 & 0.2 \\
Ciudad Mier & 25.9 & 0.4 \\
Camargo & 27.9 & 0 \\
Díaz Ordaz & 70.1 & 0 \\
Miguel Alemán & 77.4 & 1.9 \\
Reynosa & 1869.4 & 2.1 \\
Matamoros & 1526.6 & 1.6 \\
Total & & \\
\hline
\end{tabular}

Fuente: Conasupo.

oficial de promover una mayor integración entre la RFN y el resto del pais. Sin embargo, ese no fue el resultado del programa. La mayor parte de las materias primas empleadas por esas nuevas industrias era producida localmente y el principal mercado de dichas industrias era local o internacional. El principal ramo de esas firmas era la agroindustria, que junto con las de reparación y producción de materiales para construcción, representaba $50 \%$ del total de las nuevas firmas. Este tipo de empresas tienden a utilizar materiales de origen local o regional. Vale la pena notar que las firmas con mayor valor agregado, menor sacrificio fiscal y que generaron $20 \%$ del empleo, fueron las agroindustrias, precisamente el tipo de industrias que dada la importancia agrícola de la RFN y su tendencia a importar alimentos básicos pudiese haber ayudado a cambiar la estructura 


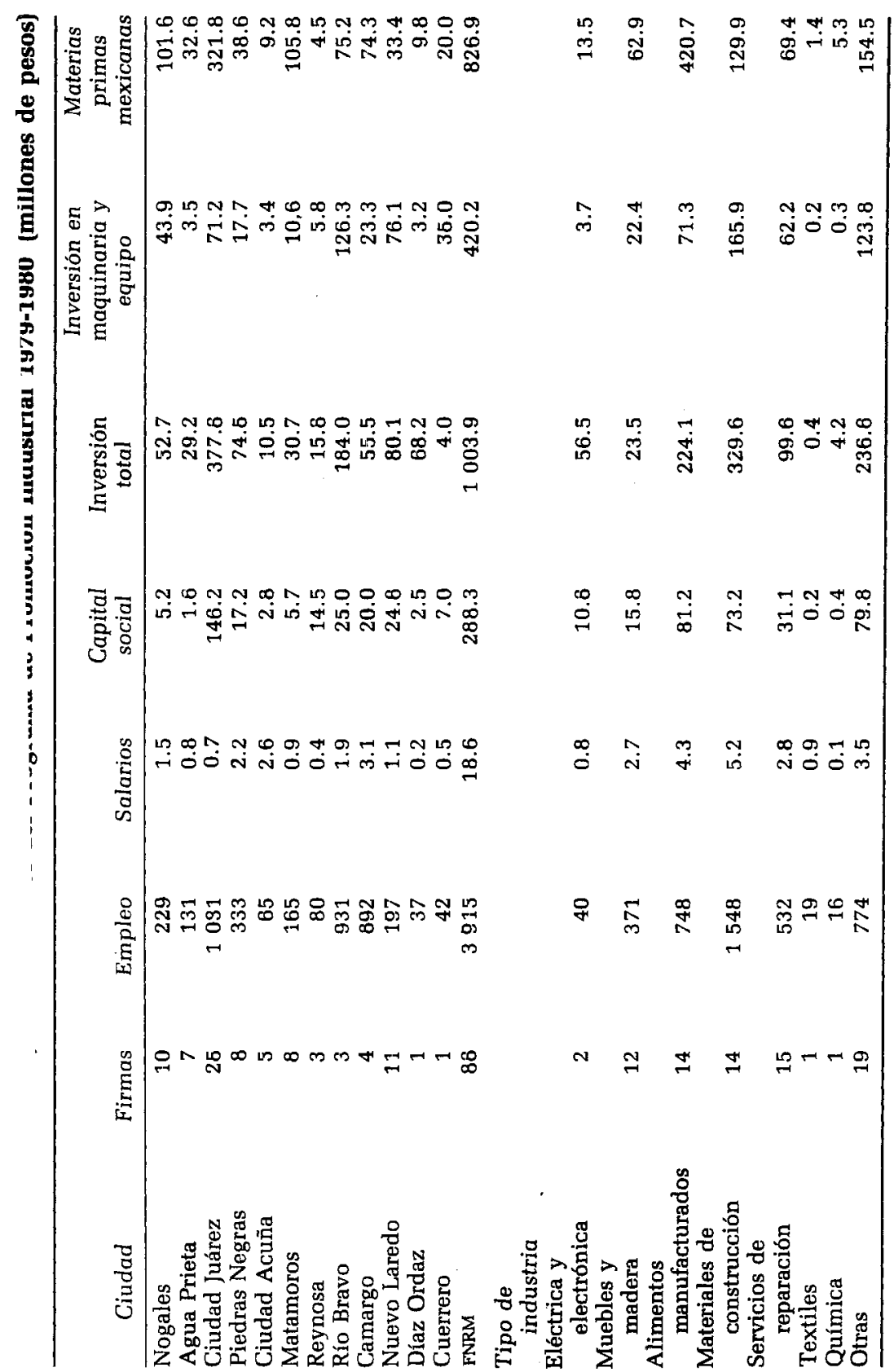




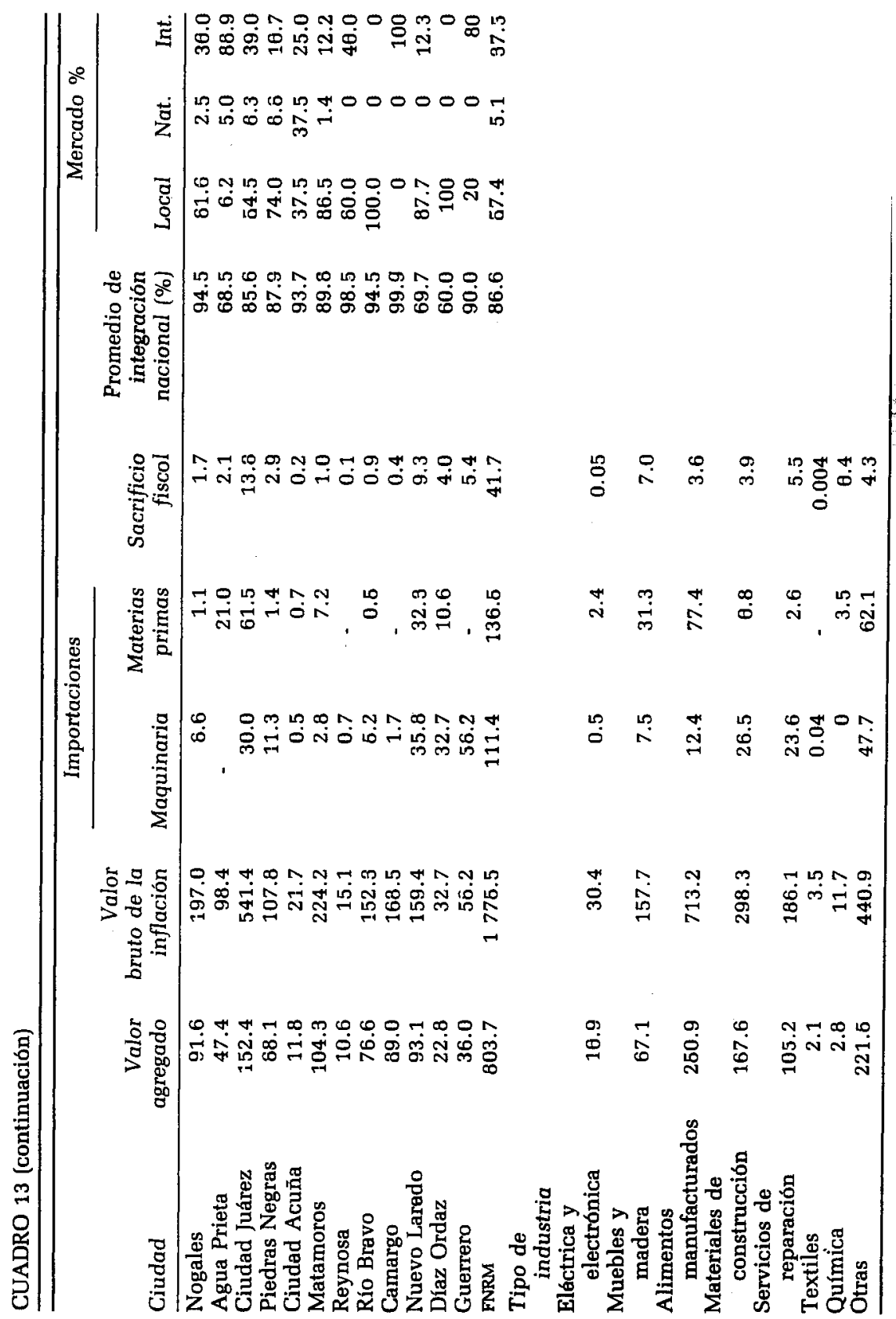


productiva de la RFN, y a cambiar un patrón de gasto donde $38-40 \%$ del ingreso familiar se destina a comprar alimentos importados. ${ }^{34}$

Desde la creación de Pronaf, el turismo ha sido considerado como una actividad que debiera ser explotada en la RFN. En realidad, turismo, en el lenguaje oficial, significa todo lo que el residente estadunidense considere diversión y pueda encontrar en el lado mexicano. Basado en datos sobre cruces fronterizos (proporcionada por el Servicio Estadunidense de Migración y Naturalización) el gobierno mexicano trató de promover las actividades que invitarían a los visitantes a pasar más tiempo, y supuestamente a gastar más dinero, en la RFN. La idea está fundamentada en que todos los cruces provenientes de los Estados Unidos son hechos por turistas potenciales. Sin embargo, esta suposición no tiene fundamento. En 1978 Codef realizo una encuesta sobre el gasto de visitantes estadounidenses a las principales ciudades fronterizas. Dependiendo de la ciudad, Il gasto promedio durante ese año fue de 101-500 pesos (4-20 d6lares). El porcentaje de visitantes que gastaban esas cantidades variaban de $30 \%$ en ظ́exicali a 50\% en Tijuana y Ciudad Juárez. Los dos primeros tenían un jatrón de gastos que semejaba la típica demanda de turismo (véase el :uadro 14).

\section{UADRO 14}

romedio de gasto de visitantes de los Estados Unidos a la RFN por ivel de ingreso (1978)

\begin{tabular}{lcccc}
\hline Ciudad & \multicolumn{4}{c}{ Pesos gastados (dólares en paréntesis) } \\
\hline & $1-100$ & $101-500$ & $501-1000$ & +1000 \\
& & & & \\
& $(1-4)$ & $(4.1-20)$ & $(20.1-40)$ & $(+40)$ \\
Ciudad Júrez & $15.0 \%$ & $49.3 \%$ & $20.8 \%$ & $14.9 \%$ \\
Nuevo Laredo & 23.7 & 37.3 & 27.0 & 22.0 \\
Matamoros & 17.3 & 40.9 & 17.1 & 24.0 \\
Reynosa & 4.3 & 43.5 & 24.7 & 27.5 \\
Tijuana & 5.6 & 30.1 & 22.0 & 43.4 \\
Mexicali & 3.1 & 30.3 & 14.9 & 47.4 \\
& & & & \\
\hline
\end{tabular}

Fuente: S. Carrillo, E. Duhan y J.M. Herrera, op. cit.

\footnotetext{
34 Comité para el Desarrollo Económico de la Península de Baja California y Parcial del Ido de Sonora, 1979; y Joaquín Lozano, "Importación doméstica de Ciudad Juárez" (Méxi1971) tomado de Salvador Carrillo, Emilio Duhau y J. Mario Herrera, Actividades terciaen la frontera norte, mimeógrafo, 1981. p. 6.
} 
El mismo estudio informa que el principal objetivo de la visita de los estadunidenses era comprar algunos bienes más baratos en México que en Estados Unidos: gasolina, licores, artículos de cuero, artesanías, servicios dentales y de reparación, etc. La única excepción fue Mexicali, donde el principal motivo era divertirse y recreación.

Estos resultados concuerdan con el hecho de que $80 \%$ de los visitantes permanecen en la RFN menos de seis horas y sólo $11 \%$ permanece hasta dos días.

La situación no parece haber cambiado mucho. En 1983 Banamex realizó una encuesta en siete ciudades fronterizas (Tijuana, Mexicali, Nogales, Ciudad Juárez, Nuevo Laredo, Reynosa y Matamoros). Casi 50\% iba de visita y sólo ocasionalmente compraban en algún comercio de menudeo; $9 \%$ iba a comprar dos veces por semana. Los principales productos comprados eran bebidas alcohólicas, alimentos (leche, café, azúcar), telas y gasolina. ${ }^{35}$ La encuesta encontró patrones similares a los establecidos por Codef: "el ingreso anual de cerca del $50 \%$ de las personas entrevistadas era inferior a 10000 dolares, factor que se traduce en un gasto per cápita limitado. Un número importante de visitantes estaba temporal, o permanentemente desempleado". ${ }^{36}$

El programa de maquila ha sido el más exitoso y también el más estudiado. Es, sin duda, la mayor fuente de empleo en la RFN y uno de los sectores más dinámicos de la economía mexicana. En 1983 había 600 plantas empleando 150000 trabajadores con un salario por hora de 86 pesos. ${ }^{37}$ Para julio de 1987 ya había 1099 plantas, que empleaban 288400 trabajadores y pagaban un salario promedio de 495 pesos por hora. ${ }^{38}$ Es pertinente destacar dos puntos asociados con los objetivos del programa de maquila: la integración al resto de la economía nacional, y proporcionar una base industrial a las ciudades fronterizas capaz de integrarlas al resto de la economía de México. Esto significaba que insumos mexicanos serían una parte importante del producto de las maquiladoras. En realidad, tal participación es mínima: en 1975 los insumos mexicanos representaban $0.8 \%$ del total de insumos usados por la maquila; para 1978 se había incrementado a $1 \%$; y para enero-julio de 1987 tal participación era de $1.6 \% .^{39}$

35 Banamex, "Profile of the US Visitor in the Border Zone" en Review of the Economic Situation of Mexico, vol. 59, 695, oct. de 1983. pp. 320-324.

${ }^{36}$ Idem, p. 320.

37 Joseph Grunwald, "The Assembly Industry in Mexico" en J. Grunwald y Kenneth Flamm (eds.), The Global Factory: Foreign Assambly in International Trade, The Brookings Institution, Washington, 1985. p. 141, cuadros 4-13.

${ }^{38}$ INEGI, A vance de información económica, industria maquiladora de exportación, diciembre de 1987.

${ }^{39}$ Grunwald, op. cit., e INEG, op. cit. 